\title{
Identification of Tilletia foetida, Ustilago tritici, and Urocystis tritici Based on Near-Infrared Spectroscopy
}

\author{
Yaqiong Zhao, ${ }^{1}$ Feng Qin, ${ }^{1}$ Fei Xu, ${ }^{2}$ Jinxing $M a,{ }^{1}$ Zhenyu Sun, ${ }^{3}$ Yuli Song, \\ Longlian Zhao, ${ }^{4}$ Junhui $\mathrm{Li}^{4}{ }^{4}$ and Haiguang Wang ${ }^{1}$ \\ ${ }^{1}$ College of Plant Protection, China Agricultural University, Beijing 100193, China \\ ${ }^{2}$ Institute of Plant Protection, Henan Academy of Agricultural Sciences, Zhengzhou 450002, China \\ ${ }^{3}$ Institute of Plant Protection, Gansu Academy of Agricultural Sciences, Lanzhou 730070, China \\ ${ }^{4}$ College of Information and Electrical Engineering, China Agricultural University, Beijing 100083, China
}

Correspondence should be addressed to Haiguang Wang; wanghaiguang@cau.edu.cn

Received 14 February 2019; Revised 10 June 2019; Accepted 9 July 2019; Published 24 July 2019

Academic Editor: Alessandra Durazzo

Copyright (C) 2019 Yaqiong Zhao et al. This is an open access article distributed under the Creative Commons Attribution License, which permits unrestricted use, distribution, and reproduction in any medium, provided the original work is properly cited.

Identifying plant pathogens for disease diagnosis and disease control strategy making is of great significance. In this study, based on near-infrared spectroscopy, a method for identifying three kinds of pathogens causing wheat smuts, including Tilletia foetida, Ustilago tritici, and Urocystis tritici, was investigated. Based on the acquired near-infrared spectral data of the teliospore samples of the three pathogens, pathogen identification models were built in different spectral regions using distinguished partial least squares (DPLS), backpropagation neural network (BPNN), and support vector machine (SVM). Satisfactory identification results were achieved using the DPLS, BPNN, and SVM models built in each of the 22 spectral regions. By contrast, the modeling effects of DPLS and SVM were better than those of BPNN. The modeling ratio of the training set to the testing set affected the identification results of the BPNN models more than those obtained using the DPLS and SVM models. In this study, a rapid, accurate, and nondestructive method was provided for plant pathogen identification, and some basis was provided for disease diagnosis, pathogen monitoring, and disease control. Moreover, some methodological references and supports were provided for identification of quarantine wheat smut fungi in plant quarantine.

\section{Introduction}

The occurrence and epidemics of plant diseases can cause severe yield losses and quality decline of agricultural products and sometimes lead to serious social problems. It is crucial to prevent and control plant diseases in a timely manner for ensuring normal agricultural production and food security. Accurate and rapid identification of plant diseases and the causal agents is the most important prerequisite of disease monitoring and early warning, which are the bases for prevention and control of plant diseases. Nowadays, morphological identification methods and molecular marker-based identification techniques are commonly used for pathogen identification. For example, morphological identification methods [1-5] and molecular biological identification methods $[2-4,6-11]$ have been developed for identification of the causal agents of many plant smuts with important economic significance in agricultural production. However, morphological identification methods highly depend on personnel experience, and it is difficult to clearly observe very small pathogens using ordinary optical microscopes, and thus identification errors easily occur. Molecular biological identification methods are highly accurate but generally require professional instruments and reagents, professional personnel to operate, and a relatively long time to achieve identification results $[12,13]$. In addition, nondestructive identification of pathogens cannot be implemented using molecular biological methods. Therefore, a new method to solve the problems in identification of plant pathogens is urgently required. To ensure the quality and safety of agricultural products and the safe production of wheat, a rapid, accurate, 
and nondestructive identification method for three kinds of wheat smut fungi based on near-infrared spectroscopy (NIRS) was explored in this present study.

NIRS, a rapid, low-cost, pollution-free, and nondestructive analytical technique, can be used to conduct both qualitative analysis and quantitative analysis of samples using material information contained in near-infrared spectra and has been widely applied in agriculture, food, petroleum, chemical, pharmacy, and other industries [1424]. Since NIRS is an indirect analytical technique, when it is applied to perform qualitative or quantitative analysis of an unknown sample, it is necessary to obtain near-infrared spectral data of a large number of known samples and then to establish a qualitative or quantitative identification model using chemometric methods.

In recent years, NIRS has been applied to detection and identification of insect pests $[25,26]$ and plant diseases [27-29]. Wu et al. [27] built an early detection model for gray mold (caused by Botrytis cinerea) on eggplant leaves based on acquired visible and near-infrared spectra using backpropagation neural network (BPNN), and an identification accuracy of $88 \%$ was achieved. For the early and rapid detection of soybean pod anthracnose (caused by Colletotrichum truncatum), integrating the successive projections algorithm and least square support vector machine (LSSVM), a disease detection model with an accuracy of $95.45 \%$ was built based on visible/near-infrared spectra by Feng et al. [28]. To realize nondestructive detection of citrus huanglongbing (caused by Candidatus liberibacter), Liu et al. [29] acquired the near-infrared spectra $\left(4000-9000 \mathrm{~cm}^{-1}\right)$ of three categories of citrus leaves including healthy leaves, nutrient-deficient leaves, and huanglongbing leaves, subsequently preprocessed the original spectral data using the methods including first derivative transformation, smoothing, and multiple scattered correction, and then built a LS-SVM model with an accuracy of $100 \%$ for identifying the three categories of leaves. At present, there are still few reports on the use of NIRS for identification and early monitoring of plant diseases and identification of plant pathogens.

In our previous studies, NIRS was used to implement early diagnosis and detection of wheat stripe rust caused by Puccinia striiformis f. sp. tritici (Pst) [30-32], qualitative discrimination of plant disease species $[30,31]$, disease severity assessment [33], and qualitative identification and quantitative analysis of Pst and P. recondita f. sp. tritici (Prt) based on NIRS $[32,34]$. In combination with a molecular biology technique, real-time polymerase chain reaction, quantitative determination of the relative contents of Pst DNA in wheat leaves in incubation period, was implemented based on NIRS [32]. In addition, the research on quantitative determination of germinability of Pst urediospores based on NIRS was conducted [35], and the effect of ultraviolet B radiation on NIRS-based identification of Pst was investigated [36]. In particular, in the study of qualitative identification and quantitative analysis of Pst and Prt, based on the acquired near-infrared spectra of pure and mixed samples of the Pst and Prt urediospores, a qualitative identification model was built using distinguished partial least squares (DPLS) and a quantitative determination model was built using quantitative partial least squares [34]. The two models demonstrated good performance, and the qualitative identification and quantitative analysis of Pst and Prt were realized based on NIRS.

Based on the studies mentioned above, the rapid and accurate identification of three kinds of wheat smut fungi including Tilletia foetida, Ustilago tritici, and Urocystis tritici causing common bunt, loose smut, and flag smut on wheat, respectively, was investigated using NIRS technology in this study. Based on the acquired near-infrared spectra of the teliospores of T. foetida, Ustilago tritici, and Urocystis tritici, pathogen identification models were built with different modeling ratios of training sets and testing sets in different modeling spectral regions using DPLS, BPNN, and support vector machine (SVM). The aim of this study was to provide a rapid, accurate, and nondestructive method for the identification of multiple kinds of plant pathogens and to provide some basis for disease diagnosis, pathogen monitoring, and disease control measure making. In addition, some methodological references were provided for identifying quarantine wheat smut fungi in plant quarantine.

\section{Materials and Methods}

2.1. Materials. T. foetida, Ustilago tritici, and Urocystis tritici were used as experimental materials. The specimens of T. foetida and Urocystis tritici were collected from wheat growing areas in Henan Province, China in 2014 and 2015. The specimens of Ustilago tritici were collected from wheat growing areas in Gansu Province, China, in 2015. For T. foetida and Urocystis tritici, diseased wheat panicles were collected. For Ustilago tritici, diseased wheat stems, leaves, and leaf sheaths with typical symptoms of wheat flag smut were collected.

For T. foetida, each of the bunt ball from the diseased wheat panicles was cracked with an inoculation needle, and the released black powdery teliospores of approximately $7-12 \mathrm{mg}$ were treated as a sample. There were 1071 bunt balls obtained in this study. For Ustilago tritici, each diseased wheat panicle was clamped with sterile forceps, then the black powdery teliospores were shacked off and landed on a piece of a smooth-surface weighing paper. The teliospores of 6-7 mg were treated as a sample, and a total of 389 teliospore samples of Ustilago tritici were obtained. For Urocystis tritici, $10 \mathrm{mg}$ of teliospores from the diseased wheat stems, leaves, and leaf sheaths were taken as a sample. A total of 30 teliospore samples of Urocystis tritici were obtained.

2.2. Acquisition of Near-Infrared Spectral Data. Using a FTNIR MPA spectrometer (Bruker, Germany), the near-infrared spectra of teliospore samples of $T$. foetida, Ustilago tritici, and Urocystis tritici were acquired. Each teliospore sample was placed into a sample cup ( $4 \mathrm{~mm}$ in diameter) for near-infrared spectral measurement using the integrating sphere diffuse reflectance method. Especially, the tightness of teliospores in the sample cup was kept as consistent as possible to reduce the errors that may be induced by 
different tightness. The spectral resolution and the number of scan processes in the measurement system were set as $8 \mathrm{~cm}^{-1}$ and 32, respectively. The near-infrared spectra in the range of 4000 to $12000 \mathrm{~cm}^{-1}$ were collected. Each teliospore sample was used for acquisition of only one near-infrared spectrum.

Totally, 1490 teliospore samples were measured and 1490 near-infrared spectra were acquired including 1071,389, and 30 spectra of T. foetida, Ustilago tritici, and Urocystis tritici, respectively. After averaging the spectral data of T. foetida, Ustilago tritici, and Urocystis tritici according to their categories, the spectral curve of each category is shown in Figure 1. There were considerable differences between the average spectra in the range of $4000-12000 \mathrm{~cm}^{-1}$ except the range of $6000-7000 \mathrm{~cm}^{-1}$. In particular, obvious differences could be found among the three average spectra in the range of $7200-12000 \mathrm{~cm}^{-1}$.

\subsection{Establishment of Pathogen Identification Models Based on} NIRS. The acquired near-infrared spectra had relatively strong random noises in high-frequency regions (Figure 1). To eliminate the effects of random noises in high-frequency regions and to select the suitable spectral region for modeling, the spectral region of $4000-12000 \mathrm{~cm}^{-1}$ and 21 spectral regions divided from the region of $4000-10000 \mathrm{~cm}^{-1}$, including 4000-5000, 4000-6000, 4000-7000, 4000-8000, 4000-9000, 4000-10000, 5000-6000, 5000-7000, 5000-8000, 5000-9000, 5000-10000, 6000-7000, 6000-8000, 6000-9000, 6000-10000, 7000-8000, 7000-9000, 7000-10000, 8000-9000, 8000-10000, and $9000-10000 \mathrm{~cm}^{-1}$, were taken as modeling spectral regions. In this study, the acquired near-infrared spectral data were processed using the two following methods: Data treatment method 1 and Data treatment method 2, and then pathogen identification models were built with three modeling ratios of training sets to testing sets (i.e., $3: 1,4: 1$ and 5 : 1) in the different spectral regions using three modeling methods including DPLS, BPNN, and SVM. The main steps for establishment of pathogen identification models are shown in Figure 2.

Data treatment method 1 was based on all the acquired near-infrared spectral data. The near-infrared spectra of each kind of pathogen were randomly selected according to modeling ratio $(3: 1,4: 1$ or $5: 1)$ and then were integrated together to form training set and testing set, respectively. The number of near-infrared spectra of each kind of pathogen in training sets and testing sets under different modeling ratios is shown in Table 1. With the modeling ratios of $3: 1,4: 1$, and $5: 1$, DPLS, BPNN, and SVM were used to build the pathogen identification models in the different modeling spectral regions, respectively. The identification accuracies of training and testing sets were used to evaluate the models. While building a DPLS model, the number of principal components was set as $1,2,3, \ldots$, or 10 . The number of neurons in the hidden layer while building a BPNN model was set as 10,50, or 100. Each BPNN model was built using the neural network toolbox of the software MATLAB 8.2 (MathWorks, Natick, MA, USA) with the default settings except for changes in the number of neurons in the hidden

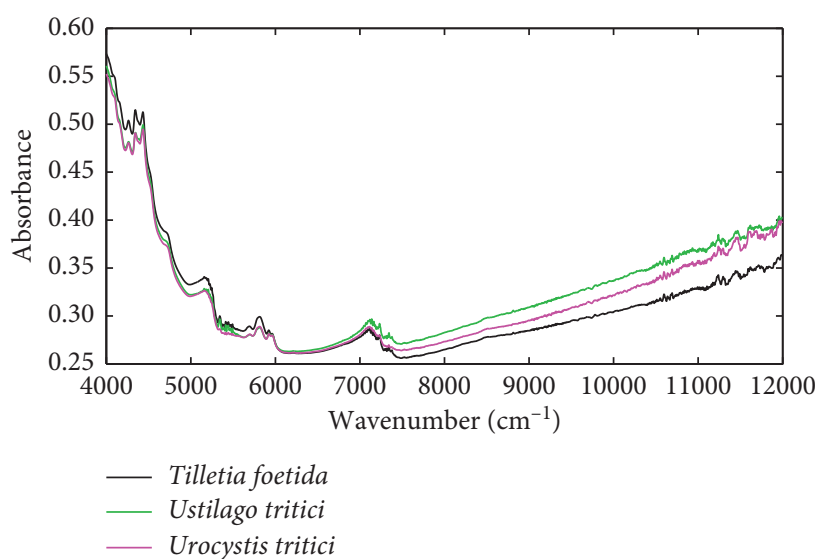

FIgURE 1: Spectral curves for the three kinds of fungi including Tilletia foetida, Ustilago tritici, and Urocystis tritici.

layer and randomly taking $90 \%$ of data from the training set for training and the remaining $10 \%$ for validation. Using C-SVM in LIBSVM package developed by the Chih-Jen Lin group from Taiwan, China [37], SVM models for pathogen identification were built with radial basis function as the kernel function. The optimal values of penalty parameter $C$ and kernel function parameter $g$ for each SVM model were searched using grid search algorithm in the range of $2^{-10}$ to $2^{10}$ with 0.8 as the searching step. Identification accuracies were calculated by 3 -fold cross validation on the training set at all points within the grid. When the identification accuracy of the training set was the highest, the values of $C$ and $g$ were selected as the optimal parameters of the SVM model.

For Data treatment method 2, to reduce the bias that may be induced by the great differences among the numbers of samples of the three kinds of pathogens, the near-infrared spectra of the samples of $T$. foetida were randomly divided into 10 groups that were labeled as TFG1, TFG2, TFG3, ..., and TFG10, and the near-infrared spectra of the samples of Ustilago tritici were also randomly divided into 10 groups that were labeled as UTG1, UTG2, UTG3, ..., and UTG10. Then, TFG1, UTG1, and all the near-infrared spectra of Urocystis tritici formed a data subset that was labeled as data subset 1. TFG2, UTG2, and all the near-infrared spectra of Urocystis tritici formed data subset 2 . In such a way, a total of 10 data subsets (including data subset 1 , data subset 2 , data subset $3, \ldots$, and data subset 10 ) were formed. The nearinfrared spectra of each kind of pathogen in each data subset were randomly selected according to modeling ratio $(3: 1,4$ : 1 or $5: 1)$ and then were integrated together to form training set and testing set, respectively. The number of near-infrared spectra of each kind of pathogen in the training and testing sets for each data subset under different modeling ratios is shown in Table 2. Based on each data subset, using DPLS, BPNN, and SVM modeling methods as described above, the pathogen identification models were built in the different modeling spectral regions when the modeling ratios of the training sets to the testing sets were $3: 1,4: 1$ and $5: 1$. The average identification accuracies and the standard deviation (SD) of the identification accuracies of training sets and testing sets on the 10 data subsets were used to evaluate the 


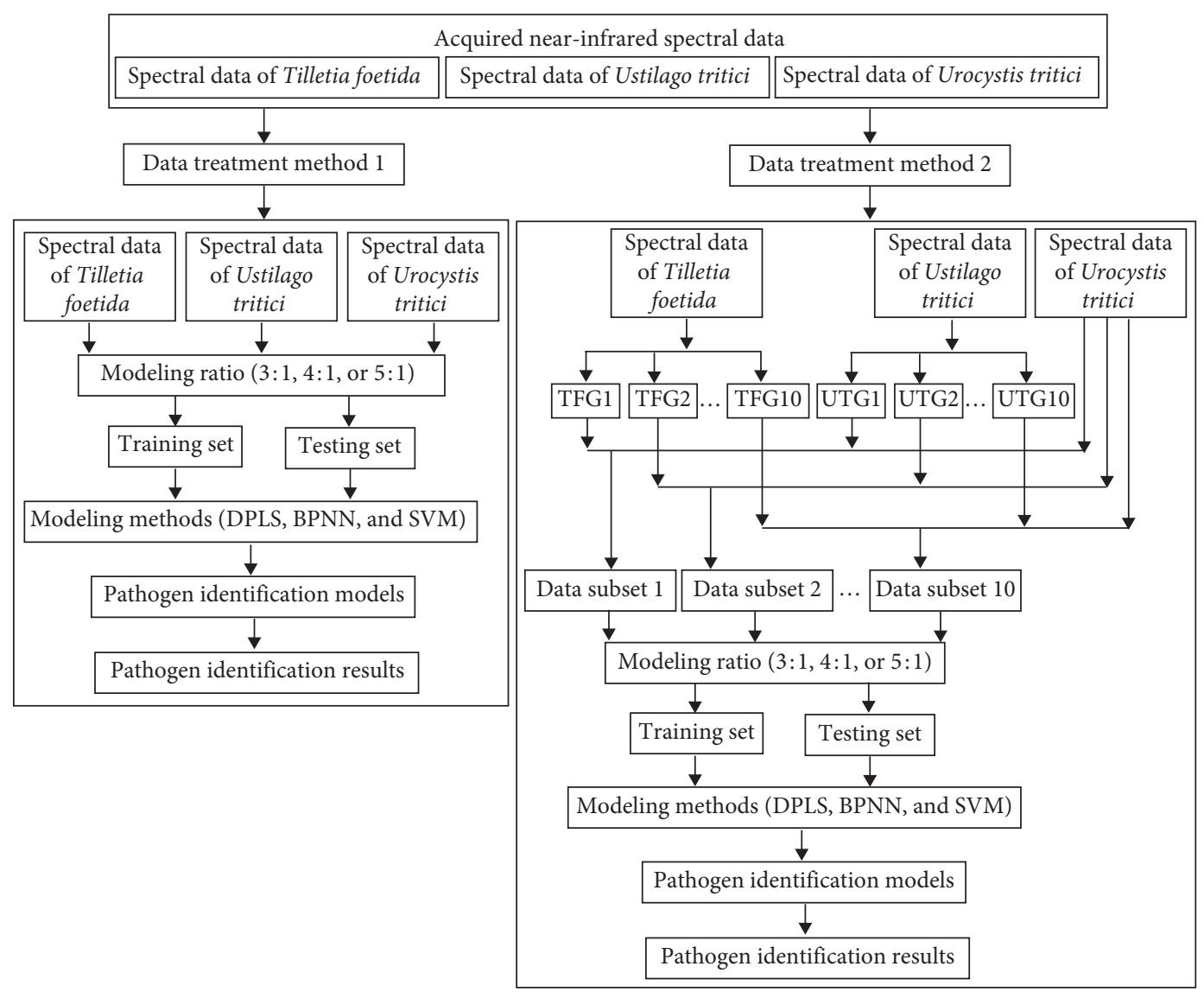

Figure 2: Work flow diagram of establishment of pathogen identification models based on near-infrared spectroscopy.

TABLE 1: Number of near-infrared spectra of each kind of pathogen in the training and testing sets under different modeling ratios when Data treatment method 1 was used.

\begin{tabular}{|c|c|c|c|c|c|c|c|c|}
\hline \multirow[b]{2}{*}{$\begin{array}{l}\text { Modeling ratio of training set } \\
\text { to testing set }\end{array}$} & \multicolumn{4}{|c|}{ Training set } & \multicolumn{4}{|c|}{ Testing set } \\
\hline & $\begin{array}{l}\text { Tilletia } \\
\text { foetida }\end{array}$ & $\begin{array}{l}\text { Ustilago } \\
\text { tritici }\end{array}$ & $\begin{array}{l}\text { Urocystis } \\
\text { tritici }\end{array}$ & $\begin{array}{c}\text { Total number of } \\
\text { samples }\end{array}$ & $\begin{array}{l}\text { Tilletia } \\
\text { foetida }\end{array}$ & $\begin{array}{l}\text { Ustilago } \\
\text { tritici }\end{array}$ & $\begin{array}{l}\text { Urocystis } \\
\text { tritici }\end{array}$ & $\begin{array}{c}\text { Total number of } \\
\text { samples }\end{array}$ \\
\hline $3: 1$ & 803 & 291 & 22 & 1116 & 268 & 98 & 8 & 374 \\
\hline $4: 1$ & 856 & 311 & 24 & 1191 & 215 & 78 & 6 & 299 \\
\hline $5: 1$ & 892 & 324 & 25 & 1241 & 179 & 65 & 5 & 249 \\
\hline
\end{tabular}

Note. There were 1490 near-infrared spectra including 1071, 389, and 30 spectra of Tilletia foetida, Ustilago tritici, and Urocystis tritici, respectively.

modeling effect. The value of SD can be calculated using the following formula:

$$
\mathrm{SD}=\sqrt{\frac{\sum_{i=1}^{n}\left(A_{i}-\bar{A}\right)^{2}}{n}}
$$

where SD is the standard deviation of the identification accuracies of training sets or testing sets on $n$ data subsets, $A_{i}$ is the identification accuracy of the training set or the testing set on the ith data subset, $\bar{A}$ is the average of the identification accuracies of training sets or testing sets on $n$ data subsets, and $n$ is the number of the data subsets. In this study, $n$ was equal to 10 .

For each modeling method (DPLS, BPNN, or SVM), when Data treatment method 1 or Data treatment method 2 was used, the optimal modeling results obtained with each modeling ratio of the training set to the testing set in each near-infrared spectral region were selected. When the DPLS models were built for pathogen identification, the optimal modeling results were selected from the identification results obtained with different numbers of principal components in a modeling spectral region, according to the identification accuracies of training sets and testing sets (Data treatment method 1) or the average identification accuracies and the SD values for training sets and test sets on the 10 data subsets (Data treatment method 2). If the same identification accuracies for training sets and testing sets were obtained when different numbers of principal components were used, the modeling effect with the minimum number of principal components was optimal. When the BPNN models were built, the optimal modeling results were selected from the results obtained with different numbers of neurons in the 
TABLE 2: Number of near-infrared spectra of each kind of pathogen in the training and testing sets for each data subset under different modeling ratios when Data treatment method 2 was used.

\begin{tabular}{|c|c|c|c|c|c|c|c|c|c|}
\hline \multirow[b]{2}{*}{$\begin{array}{l}\text { Modeling ratio of training } \\
\text { set to testing set }\end{array}$} & \multirow[b]{2}{*}{$\begin{array}{l}\text { Data } \\
\text { subset }\end{array}$} & \multicolumn{4}{|c|}{ Training set } & \multicolumn{4}{|c|}{ Testing set } \\
\hline & & $\begin{array}{l}\text { Tilletia } \\
\text { foetida } \\
\end{array}$ & $\begin{array}{l}\text { Ustilago } \\
\text { tritici }\end{array}$ & $\begin{array}{l}\text { Urocystis } \\
\text { tritici }\end{array}$ & $\begin{array}{l}\text { Total number of } \\
\text { samples }\end{array}$ & $\begin{array}{l}\text { Tilletia } \\
\text { foetida }\end{array}$ & $\begin{array}{l}\text { Ustilago } \\
\text { tritici }\end{array}$ & $\begin{array}{l}\text { Urocystis } \\
\text { tritici }\end{array}$ & $\begin{array}{c}\text { Total number of } \\
\text { samples } \\
\end{array}$ \\
\hline $3: 1$ & 1 & 80 & 29 & 22 & 131 & 27 & 10 & 8 & 45 \\
\hline $3: 1$ & 2 & 80 & 29 & 22 & 131 & 27 & 10 & 8 & 45 \\
\hline $3: 1$ & 3 & 80 & 29 & 22 & 131 & 27 & 10 & 8 & 45 \\
\hline $3: 1$ & 4 & 80 & 29 & 22 & 131 & 27 & 10 & 8 & 45 \\
\hline $3: 1$ & 5 & 80 & 29 & 22 & 131 & 27 & 10 & 8 & 45 \\
\hline $3: 1$ & 6 & 80 & 29 & 22 & 131 & 27 & 10 & 8 & 45 \\
\hline $3: 1$ & 7 & 80 & 29 & 22 & 131 & 27 & 10 & 8 & 45 \\
\hline $3: 1$ & 8 & 80 & 29 & 22 & 131 & 27 & 10 & 8 & 45 \\
\hline $3: 1$ & 9 & 80 & 29 & 22 & 131 & 27 & 10 & 8 & 45 \\
\hline $3: 1$ & 10 & 81 & 28 & 22 & 131 & 27 & 10 & 8 & 45 \\
\hline $4: 1$ & 1 & 85 & 31 & 24 & 140 & 22 & 8 & 6 & 36 \\
\hline $4: 1$ & 2 & 85 & 31 & 24 & 140 & 22 & 8 & 6 & 36 \\
\hline $4: 1$ & 3 & 85 & 31 & 24 & 140 & 22 & 8 & 6 & 36 \\
\hline $4: 1$ & 4 & 85 & 31 & 24 & 140 & 22 & 8 & 6 & 36 \\
\hline $4: 1$ & 5 & 85 & 31 & 24 & 140 & 22 & 8 & 6 & 36 \\
\hline $4: 1$ & 6 & 85 & 31 & 24 & 140 & 22 & 8 & 6 & 36 \\
\hline $4: 1$ & 7 & 85 & 31 & 24 & 140 & 22 & 8 & 6 & 36 \\
\hline $4: 1$ & 8 & 85 & 31 & 24 & 140 & 22 & 8 & 6 & 36 \\
\hline $4: 1$ & 9 & 85 & 31 & 24 & 140 & 22 & 8 & 6 & 36 \\
\hline $4: 1$ & 10 & 86 & 30 & 24 & 140 & 22 & 8 & 6 & 36 \\
\hline $5: 1$ & 1 & 89 & 32 & 25 & 146 & 18 & 7 & 5 & 30 \\
\hline $5: 1$ & 2 & 89 & 32 & 25 & 146 & 18 & 7 & 5 & 30 \\
\hline $5: 1$ & 3 & 89 & 32 & 25 & 146 & 18 & 7 & 5 & 30 \\
\hline $5: 1$ & 4 & 89 & 32 & 25 & 146 & 18 & 7 & 5 & 30 \\
\hline $5: 1$ & 5 & 89 & 32 & 25 & 146 & 18 & 7 & 5 & 30 \\
\hline $5: 1$ & 6 & 89 & 32 & 25 & 146 & 18 & 7 & 5 & 30 \\
\hline $5: 1$ & 7 & 89 & 32 & 25 & 146 & 18 & 7 & 5 & 30 \\
\hline $5: 1$ & 8 & 89 & 32 & 25 & 146 & 18 & 7 & 5 & 30 \\
\hline $5: 1$ & 9 & 89 & 32 & 25 & 146 & 18 & 7 & 5 & 30 \\
\hline $5: 1$ & 10 & 90 & 31 & 25 & 146 & 18 & 7 & 5 & 30 \\
\hline
\end{tabular}

Note. There were 1490 near-infrared spectra including 1071, 389, and 30 spectra of Tilletia foetida, Ustilago tritici, and Urocystis tritici, respectively. There were 10 data subsets, and each data subset was composed of 176 spectra.

hidden layer in a modeling spectral region, according to the identification accuracies of training sets and testing sets (Data treatment method 1) or the average identification accuracies and the SD values for training sets and testing sets on the 10 data subset (Data treatment method 2). If the same identification accuracies for training and testing sets were obtained when different numbers of neurons in the hidden layer were used, the modeling effect with the minimum number of neurons was optimal.

Moreover, when the pathogen identification models were built using DPLS, BPNN, or SVM, a comprehensive comparison of the optimal modeling results obtained in different modeling spectral regions was performed. A comparison of the modeling results obtained with Data treatment method 1 and Data treatment method 2 was also conducted.

\section{Results}

3.1. Pathogen Identification Results of the DPLS, BPNN, and SVM Models Using Data Treatment Method 1. When the acquired near-infrared spectral data were processed with
Data treatment method 1, very good performance with the identification accuracies of the training and testing sets of more than $97 \%$ was achieved using the DPLS models built with different modeling ratios in each of the 22 modeling spectral regions (Table 3). The identification accuracies of the training and testing sets reached $100 \%$ for the DPLS models built with different modeling ratios in the modeling spectral regions, except for the spectral regions of 4000-5000, 6000-7000, $8000-9000,8000-10000$, and $9000-10000 \mathrm{~cm}^{-1}$. When the DPLS models were built in the narrow spectral regions, the identification accuracies of the training and testing sets could reach $100 \%$ only for the models with different modeling ratios in the two spectral regions of $5000-6000$ and $7000-8000 \mathrm{~cm}^{-1}$. The identification accuracies of the training and testing sets could reach $100 \%$ for the DPLS models built with different modeling ratios in the relatively wide spectral regions, except for the spectral region of $8000-10000 \mathrm{~cm}^{-1}$. The results indicated that the width of modeling spectral region had certain effects on the identification results of the DPLS models. In addition, the results demonstrated that relatively low-frequency regions and relatively high-frequency regions in the acquired near-infrared spectra could decrease the identification 
TABle 3: The optimal results except those with both the identification accuracy of the training set and the identification accuracy of the testing set equal to $100 \%$ when the DPLS models for Data treatment method 1 were built with different modeling ratios in each modeling spectral region.

\begin{tabular}{lcccc}
\hline Spectral region $\left(\mathrm{cm}^{-1}\right)$ & $\begin{array}{c}\text { Modeling ratio of training } \\
\text { set to testing set }\end{array}$ & $\begin{array}{c}\text { The number of } \\
\text { principal components }\end{array}$ & $\begin{array}{c}\text { Identification accuracy of } \\
\text { training set }(\%)\end{array}$ & $\begin{array}{c}\text { Identification accuracy of } \\
\text { testing set }(\%)\end{array}$ \\
\hline $4000-5000$ & $3: 1$ & 9 & 99.91 & 90 \\
$4000-5000$ & $4: 1$ & 9 & 99.92 & 100 \\
$4000-5000$ & $5: 1$ & 10 & 99.46 & 98.67 \\
$6000-7000$ & $3: 1$ & 10 & 99.33 & 99.33 \\
$6000-7000$ & $4: 1$ & 9 & 99.44 & 98.80 \\
$6000-7000$ & $5: 1$ & 9 & 98.21 & 98.13 \\
$8000-9000$ & $3: 1$ & 8 & 98.40 & 98.33 \\
$8000-9000$ & $4: 1$ & 9 & 98.39 & 97.99 \\
$8000-9000$ & $5: 1$ & 9 & 99.91 & 99.47 \\
$8000-10000$ & $3: 1$ & 10 & 99.92 & 99.33 \\
$8000-10000$ & $4: 1$ & 8 & 99.84 & 99.60 \\
$8000-10000$ & $5: 1$ & 9 & 98.03 & 97.33 \\
$9000-10000$ & $3: 1$ & 9 & 97.98 & 97.66 \\
$9000-10000$ & $4: 1$ & 7 & 97.99 & 97.59 \\
$9000-10000$ & $5: 1$ & 9 & 9
\end{tabular}

accuracies of the training and testing sets. In particular, highfrequency regions with relatively wide ranges had some effects on the identification results of the models with different modeling ratios.

When the acquired near-infrared spectral data were processed with Data treatment method 1, the BPNN models built with different modeling ratios in each modeling spectral region performed well (Table 4). The optimal identification accuracies of the training and testing sets were $87.66 \%$ and $88.29 \%$, respectively, when the BPNN model was built with the modeling ratio equal to $4: 1$ and the number of neurons in the hidden layer equal to 10 in the spectral region of $9000-10000 \mathrm{~cm}^{-1}$. The identification accuracies of the training and testing sets reached more than $90 \%$ in other cases. When the BPNN models were built in the spectral region of $4000-12000 \mathrm{~cm}^{-1}$, the identification accuracies of the training and testing sets for the models built with the modeling ratios of $3: 1$ and $5: 1$ reached $100 \%$, and those for the model built with the modeling ratio equal to $4: 1$ and the number of neurons in the hidden layer equal to 50 were $99.83 \%$ and $100 \%$, respectively. When the BPNN models were built in the 21 spectral regions from the range of 4000 to $10000 \mathrm{~cm}^{-1}$, the optimal identification accuracies of the training sets and the testing sets for the models with different modeling ratios reached $100 \%$, except for the spectral regions of 4000-6000, 5000-6000, 5000-9000, 6000-7000, 60008000 , 6000-9000, 6000-10000, 7000-8000, 8000-9000, $8000-10000$, and $9000-10000 \mathrm{~cm}^{-1}$. For the BPNN models built in each of the 21 spectral regions from the range of $4000-10000 \mathrm{~cm}^{-1}$ except the spectral regions of $6000-7000$, $8000-9000,8000-10000$, and $9000-10000 \mathrm{~cm}^{-1}$, at least when one modeling ratio was used, both the identification accuracy of the training set and that of the testing set reached $100 \%$. For the BPNN models built in the narrow spectral regions, $4000-5000$, 5000-6000, and $7000-8000 \mathrm{~cm}^{-1}$, both the identification accuracies of the training and testing sets could reach $100 \%$. However, when the BPNN models were built in the spectral regions of $5000-6000$ and $7000-8000 \mathrm{~cm}^{-1}$, the modeling ratio affected the modeling results. For the BPNN models built in the spectral region of $5000-6000 \mathrm{~cm}^{-1}$, when the modeling ratios were $3: 1,4: 1$, and $5: 1$, the identification accuracies of the training sets were $100 \%, 97.98 \%$, and $99.92 \%$, respectively, and those of the testing sets were $100 \%, 97.99 \%$, and $100 \%$, respectively. For the BPNN models built with the modeling ratios of $3: 1,4: 1$, and $5: 1$ in the spectral region of $7000-8000 \mathrm{~cm}^{-1}$, the identification accuracies of the training sets were $100 \%, 97.98 \%$, and $100 \%$, respectively, and those of the testing sets were $100 \%, 97.99 \%$, and $100 \%$, respectively.

When Data treatment method 1 was used, the SVM models that were built with different modeling ratios in each modeling spectral region presented very good performances, with the optimal identification accuracies of the training and testing sets of more than 99\% (Table 5). For the SVM models that were built in the modeling spectral regions, except the spectral region of $9000-10000 \mathrm{~cm}^{-1}$, the identification accuracies of $100 \%$ of the training and testing sets were achieved at least when one modeling ratio was used. When the SVM models were built in the narrow spectral regions of 4000-5000, 6000-7000, 7000-8000, and $8000-9000 \mathrm{~cm}^{-1}$, both the identification accuracies of the training sets and those of the testing sets reached $100 \%$ when each of the three modeling ratios was used. For the SVM models built in the spectral region of 5000$6000 \mathrm{~cm}^{-1}$, when the modeling ratios were $3: 1$ and $4: 1$, the optimal identification accuracies of the training sets were $99.91 \%$ and $100 \%$, respectively, and those of the testing sets were $100 \%$ and $99.67 \%$, respectively, and when the modeling ratio was $5: 1$, both the optimal identification accuracy of the training set and that of the testing set were $100 \%$. For the SVM models built in the spectral region of $9000-10000 \mathrm{~cm}^{-1}$, the optimal identification accuracy of the training set was $100 \%$ and that of the testing set was $99.73 \%$ when the modeling ratio was $3: 1$; when the modeling ratio was $4: 1$, the optimal identification accuracies of the training set and the testing set were $99.92 \%$ and $100 \%$, respectively; and when the modeling ratio was $5: 1$, 
TABLE 4: The optimal results except those with both the identification accuracy of the training set and the identification accuracy of the testing set equal to $100 \%$ when the BPNN models for Data treatment method 1 were built with different modeling ratios in each modeling spectral region.

\begin{tabular}{|c|c|c|c|c|}
\hline Spectral region $\left(\mathrm{cm}^{-1}\right)$ & $\begin{array}{c}\text { Modeling ratio of } \\
\text { training set to testing set }\end{array}$ & $\begin{array}{c}\text { The number of neurons in } \\
\text { the hidden layer }\end{array}$ & $\begin{array}{l}\text { Identification accuracy of } \\
\text { training set }(\%)\end{array}$ & $\begin{array}{c}\text { Identification accuracy } \\
\text { of testing set }(\%)\end{array}$ \\
\hline $4000-12000$ & $4: 1$ & 50 & 99.83 & 100 \\
\hline $4000-6000$ & $4: 1$ & 10 & 97.98 & 97.99 \\
\hline $4000-6000$ & $5: 1$ & 10 & 97.99 & 97.99 \\
\hline $5000-6000$ & $4: 1$ & 10 & 97.98 & 97.99 \\
\hline $5000-6000$ & $5: 1$ & 100 & 99.92 & 100 \\
\hline $5000-9000$ & $3: 1$ & 10 & 98.03 & 97.86 \\
\hline $6000-7000$ & $3: 1$ & 100 & 98.03 & 97.59 \\
\hline $6000-7000$ & $4: 1$ & 50 & 97.98 & 97.99 \\
\hline $6000-7000$ & $5: 1$ & 10 & 97.99 & 97.59 \\
\hline $6000-8000$ & $3: 1$ & 50 & 98.03 & 97.86 \\
\hline $6000-9000$ & $4: 1$ & 10 & 97.98 & 97.99 \\
\hline $6000-10000$ & $3: 1$ & 10 & 98.03 & 97.86 \\
\hline $6000-10000$ & $4: 1$ & 10 & 97.98 & 97.99 \\
\hline $7000-8000$ & $4: 1$ & 10 & 97.98 & 97.99 \\
\hline $8000-9000$ & $3: 1$ & 50 & 98.03 & 97.86 \\
\hline $8000-9000$ & $4: 1$ & 50 & 97.98 & 97.99 \\
\hline $8000-9000$ & $5: 1$ & 50 & 97.99 & 97.99 \\
\hline $8000-10000$ & $3: 1$ & 100 & 98.03 & 97.86 \\
\hline $8000-10000$ & $4: 1$ & 50 & 97.98 & 97.99 \\
\hline $8000-10000$ & $5: 1$ & 10 & 97.99 & 97.99 \\
\hline $9000-10000$ & $3: 1$ & 50 & 92.11 & 91.98 \\
\hline $9000-10000$ & $4: 1$ & 10 & 87.66 & 88.29 \\
\hline $9000-10000$ & $5: 1$ & 50 & 97.58 & 97.19 \\
\hline
\end{tabular}

TABLE 5: The optimal results except those with both the identification accuracy of the training set and the identification accuracy of the testing set equal to $100 \%$ when the SVM models for Data treatment method 1 were built with different modeling ratios in each modeling spectral region.

\begin{tabular}{lccccc}
\hline Spectral region $\left(\mathrm{cm}^{-1}\right)$ & $\begin{array}{c}\text { Modeling ratio of training } \\
\text { set to testing set }\end{array}$ & \multicolumn{2}{c}{ Optimal parameters } & $\begin{array}{c}\text { Identification accuracy } \\
\text { of training set }(\%)\end{array}$ & $\begin{array}{c}\text { Identification accuracy of } \\
\text { testing set }(\%)\end{array}$ \\
\hline $4000-12000$ & $3: 1$ & $g$ & 100 & 99.73 \\
$4000-6000$ & $4: 1$ & 1.3195 & 64.0000 & 100 & 99.67 \\
$4000-10000$ & $3: 1$ & 0.4353 & 6.9644 & 100 & 99.73 \\
$5000-6000$ & $3: 1$ & 4.0000 & 36.7583 & 99.91 & 100 \\
$5000-6000$ & $4: 1$ & 1.3195 & 337.7940 & 100 & 99.67 \\
$5000-10000$ & $3: 1$ & 0.4353 & 12.1257 & 100 & 99.73 \\
$5000-10000$ & $5: 1$ & 0.7579 & 111.4305 & 100 & 99.60 \\
$6000-8000$ & $3: 1$ & 6.9644 & 64.0000 & 100 & 99.73 \\
$6000-8000$ & $5: 1$ & 2.2974 & 588.1336 & 100 & 99.20 \\
$6000-9000$ & $3: 1$ & 1.3195 & 21.1121 & 100 & 99.47 \\
$6000-9000$ & $5: 1$ & 1.3195 & 337.7940 & 100 & 99.20 \\
$6000-10000$ & $3: 1$ & 1.3195 & 12.1257 & 99.91 & 99.73 \\
$9000-10000$ & $3: 1$ & 64.0000 & 111.4305 & 100 & 99.73 \\
$9000-10000$ & $4: 1$ & 588.1336 & 4.0000 & 99.92 & 100 \\
$9000-10000$ & $5: 1$ & 12.1257 & 337.7940 & 100 & 99.60 \\
\hline
\end{tabular}

those of the training set and the testing set were $100 \%$ and $99.60 \%$, respectively.

As described above, satisfactory results could be obtained using the pathogen identification models built using DPLS, BPNN, and SVM in different spectral regions. Compared with the DPLS and BPNN modeling methods, the identification accuracies of the training and testing sets could reach $100 \%$ in more spectral regions when the pathogen identification models were built using SVM. By contrast, the effects of the modeling ratio on the identification results of the models built using BPNN and SVM were greater than those on the identification results of the models built using DPLS.

3.2. Pathogen Identification Results of the DPLS, SVM, and BPNN Models Using Data Treatment Method 2. When Data treatment method 2 was used, very satisfactory modeling results were achieved using the DPLS models built on each data subset with different modeling ratios in each modeling 
spectral region. The average identification accuracies of the training sets and the testing sets on the 10 data subsets reached more than 98\% (Table 6). Except for the models built with the modeling ratio of $3: 1$ in the spectral region of $6000-7000 \mathrm{~cm}^{-1}$ and the models built on each data subset with the three modeling ratios in the spectral region of $8000-9000$ or $9000-10000 \mathrm{~cm}^{-1}$, the average identification accuracies of the training sets and the testing sets on the 10 data subsets reached $100 \%$ for the DPLS models built on each data subset with different modeling ratios in each of the other modeling spectral regions. For the DPLS models built in the narrow spectral region of 4000-5000, 5000-6000, $6000-7000$, or $7000-8000 \mathrm{~cm}^{-1}$, both the average identification accuracies of the training and testing sets on the 10 data subsets reached $100 \%$, when one or more than one modeling ratios were used. By contrast, there was some reduction in the average identification accuracies of the training sets and the testing sets on the 10 data subsets when the DPLS models were built in the narrow high-frequency region of $8000-9000$ or $9000-10000 \mathrm{~cm}^{-1}$, demonstrating that high-frequency regions had an impact on the modeling results. Although both the average identification accuracies of the training sets and those of the testing sets on the 10 data subsets did not reach $100 \%$ for the models built with the modeling ratio of $3: 1$ in the spectral region of $6000-7000 \mathrm{~cm}^{-1}$ and for those built with each modeling ratio in the spectral region of $8000-9000$ or $9000-10000 \mathrm{~cm}^{-1}$, the average identification accuracies were still very high, and the SD values of the identification accuracies for the 10 data subsets were very small. The results indicated that satisfactory identification performance could be achieved using the DPLS models based on NIRS and that the models had high stability.

When Data treatment method 2 was used, satisfactory identification results could be obtained using the BPNN models built on each data subset in each modeling spectral region (Table 7), but the modeling ratio had a great influence on the identification results of the models. For the BPNN models built in the spectral region of $4000-8000 \mathrm{~cm}^{-1}$, both the average identification accuracy of the training sets and that of the testing sets on the 10 data subsets reached $100 \%$ when the modeling ratio was $4: 1$ or $5: 1$. When the BPNN models were built with the modeling ratio of $5: 1$ in the spectral region of $5000-6000 \mathrm{~cm}^{-1}$ on the 10 data subsets, both the average identification accuracy of the training sets and that of the testing sets reached $100 \%$. When the BPNN models were built with the modeling ratio of $3: 1$ in the spectral region of $5000-10000 \mathrm{~cm}^{-1}$ on the 10 data subsets, both the average identification accuracy of the training sets and that of the testing sets reached $100 \%$. For the models built with the modeling ratio of $3: 1$ or $5: 1$ in the spectral region of $4000-5000 \mathrm{~cm}^{-1}$, the ones built with the modeling ratio of $4: 1$ in the spectral region of $5000-6000 \mathrm{~cm}^{-1}$, the ones built with the modeling ratio of $3: 1$ or $5: 1$ in the spectral region of $6000-7000 \mathrm{~cm}^{-1}$, and the ones built with the modeling ratio of $3: 1$ in the spectral region of $8000-10000 \mathrm{~cm}^{-1}$, the SD values of the identification accuracies of the training and testing sets were both relatively high, indicating poor modeling effects.
When Data treatment method 2 was used, the SVM models built on the 10 data subsets, with each modeling ratio in each modeling spectral region, presented very good performance with the averages of the identification accuracies of the training sets and the testing sets of more than $98 \%$ (Table 8 ). Very small SD values were obtained for the identification accuracies of the training and testing sets. For the SVM models built on the 10 data subsets with the modeling ratio of $5: 1$ in the spectral region of $4000-7000 \mathrm{~cm}^{-1}$, the average identification accuracies of the training and testing sets were $99.93 \%$ and $100 \%$, respectively, and the $\mathrm{SD}$ values for the training and testing sets were 0.002040 and 0 , respectively. For the SVM models built on the 10 data subsets with the modeling ratio of $5: 1$ in the spectral region of $4000-12000 \mathrm{~cm}^{-1}$, the average identification accuracies of the training and testing sets were $99.86 \%$ and $100 \%$, respectively, and the SD values for the training and testing sets were 0.002720 and 0 , respectively. For the SVM models built on the 10 data subsets with the modeling ratio of $4: 1$ in the spectral region of $5000-6000 \mathrm{~cm}^{-1}$, the average identification accuracies of the training and testing sets were $99.86 \%$ and $100 \%$, respectively, and the SD values for the training and testing sets were 0.004290 and 0 , respectively. The identification results of the models in the three cases above were the best. By contrast, the worst identification results were obtained when the models were built on the 10 data subsets with the modeling ratio of $5: 1$ or $3: 1$ in the spectral region of $8000-9000 \mathrm{~cm}^{-1}$ and on the 10 data subsets with the modeling ratio of $4: 1$ in the spectral region of $9000-10000 \mathrm{~cm}^{-1}$. For the models built in these three cases, the average identification accuracies of the training sets were $99.73 \%, 99.77 \%$, and $99.57 \%$, respectively, and the SD values for the training sets were 0.006261, 0.004893 , and 0.005715 , respectively; the average identification accuracies of the testing sets were $98.33 \%$, 98.00\%, and $98.06 \%$, respectively, and the SD values for the testing sets were $0.02236,0.01554$, and 0.03298 , respectively.

The results showed that the pathogen identification models built using DPLS performed better than those built using BPNN or SVM when Data treatment method 2 was used. The modeling effect of DPLS on each data subset was more stable than that of BPNN. When the pathogen identification models were built using BPNN in the spectral region of $4000-5000,5000-6000,6000-7000$, or $8000-10000 \mathrm{~cm}^{-1}$, greater SD values of the identification accuracies of the training and testing sets were obtained. Although the modeling effect of SVM was not as good as that of DPLS, very satisfactory identification accuracies of the training and testing sets were achieved using the SVM models built on each data subset.

3.3. Comparison of Modeling Results Obtained with Data Treatment Methods 1 and 2. The modeling effect using DPLS with Data treatment method 2 was better than that achieved with Data treatment method 1. When Data treatment method 2 was used, the average identification accuracies of the training and testing sets did not simultaneously reach $100 \%$ for the DPLS models built on the 10 data subsets with 
TABLE 6: The optimal results except the average identification accuracies and the standard deviations of the identification accuracies for the 10 data subsets for the training sets and the testing sets were $100 \%$ and 0 when the DPLS models for Data treatment method 2 were built with different modeling ratios in each modeling spectral region.

\begin{tabular}{|c|c|c|c|c|c|c|}
\hline \multirow[b]{2}{*}{$\begin{array}{l}\text { Spectral } \\
\text { region } \\
\left(\mathrm{cm}^{-1}\right)\end{array}$} & \multirow[b]{2}{*}{$\begin{array}{l}\text { Modeling ratio } \\
\text { of training set to } \\
\text { testing set }\end{array}$} & \multirow[b]{2}{*}{$\begin{array}{l}\text { The number of } \\
\text { principal } \\
\text { components }\end{array}$} & \multicolumn{2}{|c|}{ Training sets } & \multicolumn{2}{|c|}{ Testing sets } \\
\hline & & & $\begin{array}{c}\text { Average } \\
\text { identification } \\
\text { accuracy for the } 10 \\
\text { data subsets (\%) }\end{array}$ & $\begin{array}{l}\text { Standard deviation } \\
\text { of the identification } \\
\text { accuracies for the } 10 \\
\text { data subsets }\end{array}$ & $\begin{array}{c}\text { Average } \\
\text { identification } \\
\text { accuracy for the } 10 \\
\text { data subsets }(\%)\end{array}$ & $\begin{array}{l}\text { Standard deviation } \\
\text { of the identification } \\
\text { accuracies for the } 10 \\
\text { data subsets }\end{array}$ \\
\hline $6000-7000$ & $3: 1$ & 7 & 100 & 0 & 99.78 & 0.006660 \\
\hline $8000-9000$ & $3: 1$ & 6 & 100 & 0 & 99.78 & 0.006660 \\
\hline $8000-9000$ & $4: 1$ & 6 & 100 & 0 & 99.44 & 0.01112 \\
\hline $8000-9000$ & $5: 1$ & 6 & 100 & 0 & 99.67 & 0.009990 \\
\hline 9000-10000 & $3: 1$ & 5 & 99.70 & 0.006994 & 98.45 & 0.01734 \\
\hline $9000-10000$ & $4: 1$ & 6 & 100 & 0 & 98.61 & 0.02241 \\
\hline $9000-10000$ & $5: 1$ & 5 & 99.66 & 0.01026 & 99.33 & 0.01332 \\
\hline
\end{tabular}

each modeling ratio only in two spectral regions (8000-9000 and $9000-10000 \mathrm{~cm}^{-1}$ ). When Data treatment method 1 was used, both the identification accuracy of the training set and that of the testing set were less than $100 \%$ for the DPLS models built with each modeling ratio in five spectral regions $(4000-5000,6000-7000,8000-9000,8000-10000$, and $\left.9000-10000 \mathrm{~cm}^{-1}\right)$.

When Data treatment method 1 was used, the optimal accuracies of the training and testing sets could reach more than $97 \%$ for the BPNN models built in different spectral regions. Among the identification results obtained using the BPNN models built with different modeling ratio in each spectral region, both the optimal accuracy of the training set and that of the testing set were less than $97 \%$, only for the models built with the modeling ratio of $3: 1$ or $4: 1$ in the spectral region of $9000-10000 \mathrm{~cm}^{-1}$. However, when Data treatment method 2 was used, relatively great differences were observed between the average identification accuracies of the training sets and between the average identification accuracies of the testing sets for the BPNN models built on the 10 data subsets in different modeling spectral regions. Among the selected optimal identification results, the range of the average identification accuracies of the training sets was $88.77-100 \%$ and the range of the average identification accuracies of the testing sets was $87.67-100 \%$. In addition, when Data treatment method 2 was used, the modeling ratio greatly influenced the identification results of the BPNN models. Relatively large identification accuracy SD values of the training and testing sets were obtained when the BPNN models were built on the 10 data subsets with one or two modeling ratios in some spectral regions (4000-5000, $5000-6000,6000-7000$, and $8000-10000 \mathrm{~cm}^{-1}$ ). This indicated that the poor modeling effects were achieved on some data subsets using BPNN and that there were relatively great differences both between the identification accuracies of the training sets and between the identification accuracies of the testing sets for the 10 BPNN models built with certain modeling ratio in certain modeling spectral region. For instance, when Data treatment method 2 was used and the BPNN models were built in the spectral region of 4000$5000 \mathrm{~cm}^{-1}$ on the 10 data subsets with a ratio of the training set to the testing set of $3: 1$, the optimal identification results
(Figure 3) were achieved with the number of neurons in the hidden layer equal to 50 . The SD values of the identification accuracies of the training and testing sets on the 10 data subsets were 0.1541 and 0.1508 , respectively. Relatively low identification accuracies of the training and testing sets were obtained for the BPNN models built on data subset 1 and data subset 2 . For the BPNN model built on data subset 1 , the identification accuracies of the training and testing sets were $70.23 \%$ and $66.67 \%$, respectively. For the BPNN model built on data subset 2 , the identification accuracies of the training and testing sets were $54.20 \%$ and $57.78 \%$, respectively. The results indicated that these two models presented poor performance in pathogen identification.

When Data treatment method 1 or Data treatment method 2 was used, the built SVM models presented very good performance with very high identification accuracies of both the training sets and the testing sets. In particular, when Data treatment method 2 was used, for the SVM models built on the 10 data subsets, very small SD values of the identification accuracies of the training and testing sets were obtained. It was demonstrated that very satisfactory identification results could be achieved using the SVM models built on each data subset and that this performance had very high stability.

\section{Conclusions and Discussion}

The application of NIRS to the identification of three kinds of wheat smut pathogens, including T. foetida, Ustilago tritici, and Urocystis tritici, was investigated in this study. The acquired near-infrared spectral data were processed using Data treatment method 1 and Data treatment method 2 to form the training and testing sets. Then, the DPLS, BPNN, and SVM models for pathogen identification were built in 22 spectral regions. Using Data treatment method 1 or Data treatment method 2, satisfactory identification results were achieved when each of the three modeling methods was used for model-building in different spectral regions. By contrast, the modeling effect of DPLS was the most stable, followed by that of SVM and that of BPNN was the worst. In this study, a rapid, accurate, and nondestructive method for the identification of the three kinds of wheat 
TABLE 7: Pathogen identification results of the BPNN models built with different modeling ratios in each modeling spectral region when Data treatment method 2 was used.

\begin{tabular}{|c|c|c|c|c|c|c|}
\hline \multirow[b]{2}{*}{$\begin{array}{l}\text { Spectral } \\
\text { region } \\
\left(\mathrm{cm}^{-1}\right)\end{array}$} & \multirow[b]{2}{*}{$\begin{array}{l}\text { Modeling ratio } \\
\text { of training set to } \\
\text { testing set }\end{array}$} & \multirow[b]{2}{*}{$\begin{array}{l}\text { The number of } \\
\text { neurons in the } \\
\text { hidden layer }\end{array}$} & \multicolumn{2}{|c|}{ Training sets } & \multicolumn{2}{|c|}{ Testing sets } \\
\hline & & & $\begin{array}{c}\text { Average } \\
\text { identification } \\
\text { accuracy for the } 10 \\
\text { data subsets }(\%)\end{array}$ & $\begin{array}{l}\text { Standard deviation } \\
\text { of the identification } \\
\text { accuracies for the } \\
10 \text { data subsets }\end{array}$ & $\begin{array}{c}\text { Average } \\
\text { identification } \\
\text { accuracy for the } 10 \\
\text { data subsets }(\%)\end{array}$ & $\begin{array}{l}\text { Standard deviation } \\
\text { of the identification } \\
\text { accuracies for the } \\
10 \text { data subsets }\end{array}$ \\
\hline $4000-12000$ & $3: 1$ & 100 & 99.70 & 0.006994 & 99.78 & 0.006660 \\
\hline $4000-12000$ & $4: 1$ & 10 & 98.00 & 0.04237 & 97.22 & 0.04648 \\
\hline $4000-12000$ & $5: 1$ & 50 & 98.02 & 0.04058 & 97.67 & 0.05176 \\
\hline $4000-5000$ & $3: 1$ & 50 & 92.14 & 0.1541 & 92.00 & 0.1508 \\
\hline $4000-5000$ & $4: 1$ & 100 & 96.57 & 0.04367 & 96.39 & 0.04488 \\
\hline $4000-5000$ & $5: 1$ & 100 & 92.88 & 0.1175 & 93.33 & 0.1183 \\
\hline $4000-6000$ & $3: 1$ & 50 & 99.54 & 0.009770 & 99.56 & 0.01332 \\
\hline $4000-6000$ & $4: 1$ & 50 & 99.71 & 0.008580 & 99.44 & 0.01668 \\
\hline $4000-6000$ & $5: 1$ & 10 & 99.59 & 0.01024 & 99.33 & 0.01332 \\
\hline $4000-7000$ & $3: 1$ & 10 & 98.02 & 0.04279 & 97.78 & 0.04662 \\
\hline $4000-7000$ & $4: 1$ & 50 & 95.29 & 0.08590 & 95.00 & 0.08766 \\
\hline $4000-7000$ & $5: 1$ & 50 & 99.59 & 0.01024 & 99.67 & 0.009990 \\
\hline $4000-8000$ & $3: 1$ & 10 & 99.31 & 0.01617 & 99.33 & 0.01017 \\
\hline $4000-8000$ & $4: 1$ & 50 & 100 & 0 & 100 & 0 \\
\hline $4000-8000$ & $5: 1$ & 50 & 100 & 0 & 100 & 0 \\
\hline $4000-9000$ & $3: 1$ & 10 & 99.92 & 0.002280 & 99.78 & 0.006660 \\
\hline $4000-9000$ & $4: 1$ & 10 & 99.57 & 0.009156 & 99.17 & 0.01780 \\
\hline $4000-9000$ & $5: 1$ & 50 & 99.93 & 0.002040 & 99.67 & 0.009990 \\
\hline $4000-10000$ & $3: 1$ & 10 & 99.77 & 0.004893 & 99.78 & 0.006660 \\
\hline $4000-10000$ & $4: 1$ & 10 & 99.64 & 0.007314 & 99.44 & 0.01668 \\
\hline $4000-10000$ & $5: 1$ & 10 & 99.73 & 0.006261 & 100 & 0 \\
\hline $5000-6000$ & $3: 1$ & 50 & 99.54 & 0.01143 & 99.11 & 0.02038 \\
\hline $5000-6000$ & $4: 1$ & 50 & 95.14 & 0.1272 & 94.44 & 0.1400 \\
\hline $5000-6000$ & $5: 1$ & 50 & 100 & 0 & 100 & 0 \\
\hline $5000-7000$ & $3: 1$ & 10 & 99.62 & 0.009181 & 99.33 & 0.01421 \\
\hline $5000-7000$ & $4: 1$ & 10 & 99.29 & 0.01153 & 98.89 & 0.01844 \\
\hline $5000-7000$ & $5: 1$ & 10 & 97.67 & 0.05708 & 97.33 & 0.05925 \\
\hline $5000-8000$ & $3: 1$ & 10 & 99.85 & 0.004590 & 99.56 & 0.008880 \\
\hline $5000-8000$ & $4: 1$ & 50 & 99.86 & 0.004290 & 99.44 & 0.01112 \\
\hline $5000-8000$ & $5: 1$ & 10 & 99.80 & 0.006150 & 100 & 0 \\
\hline $5000-9000$ & $3: 1$ & 100 & 99.92 & 0.002280 & 99.78 & 0.006660 \\
\hline $5000-9000$ & $4: 1$ & 50 & 99.79 & 0.004573 & 99.44 & 0.01668 \\
\hline $5000-9000$ & $5: 1$ & 100 & 99.80 & 0.004381 & 99.67 & 0.009990 \\
\hline $5000-10000$ & $3: 1$ & 50 & 100 & 0 & 100 & 0 \\
\hline $5000-10000$ & $4: 1$ & 50 & 100 & 0 & 99.72 & 0.008340 \\
\hline $5000-10000$ & $5: 1$ & 50 & 99.66 & 0.01026 & 99.67 & 0.009990 \\
\hline $6000-7000$ & $3: 1$ & 50 & 94.28 & 0.1015 & 94.22 & 0.1010 \\
\hline $6000-7000$ & $4: 1$ & 50 & 95.72 & 0.08484 & 94.72 & 0.08094 \\
\hline $6000-7000$ & $5: 1$ & 50 & 88.77 & 0.1922 & 87.67 & 0.1700 \\
\hline $6000-8000$ & $3: 1$ & 50 & 100 & 0 & 99.78 & 0.006660 \\
\hline $6000-8000$ & $4: 1$ & 50 & 99.86 & 0.004290 & 99.44 & 0.01112 \\
\hline $6000-8000$ & $5: 1$ & 50 & 97.88 & 0.04379 & 97.00 & 0.06046 \\
\hline $6000-9000$ & $3: 1$ & 100 & 98.24 & 0.04069 & 98.00 & 0.04604 \\
\hline $6000-9000$ & $4: 1$ & 50 & 99.86 & 0.002840 & 99.44 & 0.01112 \\
\hline $6000-9000$ & $5: 1$ & 50 & 99.93 & 0.002040 & 99.67 & 0.009990 \\
\hline $6000-10000$ & $3: 1$ & 100 & 99.47 & 0.01186 & 99.33 & 0.01421 \\
\hline $6000-10000$ & $4: 1$ & 50 & 97.93 & 0.04233 & 96.67 & 0.04779 \\
\hline $6000-10000$ & $5: 1$ & 10 & 99.04 & 0.02435 & 99.33 & 0.01332 \\
\hline $7000-8000$ & $3: 1$ & 50 & 99.85 & 0.003040 & 99.33 & 0.01421 \\
\hline $7000-8000$ & $4: 1$ & 50 & 99.86 & 0.004290 & 99.44 & 0.01668 \\
\hline $7000-8000$ & $5: 1$ & 50 & 99.93 & 0.002040 & 99.00 & 0.02135 \\
\hline $7000-9000$ & $3: 1$ & 50 & 98.24 & 0.04040 & 97.33 & 0.04534 \\
\hline $7000-9000$ & $4: 1$ & 50 & 98.43 & 0.03805 & 97.22 & 0.04648 \\
\hline $7000-9000$ & $5: 1$ & 50 & 97.95 & 0.04029 & 97.33 & 0.05122 \\
\hline $7000-10000$ & $3: 1$ & 50 & 95.65 & 0.08542 & 95.56 & 0.08374 \\
\hline
\end{tabular}


TABLE 7: Continued.

\begin{tabular}{|c|c|c|c|c|c|c|}
\hline \multirow[b]{2}{*}{$\begin{array}{l}\text { Spectral } \\
\text { region } \\
\left(\mathrm{cm}^{-1}\right)\end{array}$} & \multirow[b]{2}{*}{$\begin{array}{l}\text { Modeling ratio } \\
\text { of training set to } \\
\text { testing set }\end{array}$} & \multirow[b]{2}{*}{$\begin{array}{l}\text { The number of } \\
\text { neurons in the } \\
\text { hidden layer }\end{array}$} & \multicolumn{2}{|c|}{ Training sets } & \multicolumn{2}{|c|}{ Testing sets } \\
\hline & & & $\begin{array}{c}\text { Average } \\
\text { identification } \\
\text { accuracy for the } 10 \\
\text { data subsets (\%) }\end{array}$ & $\begin{array}{l}\text { Standard deviation } \\
\text { of the identification } \\
\text { accuracies for the } \\
10 \text { data subsets }\end{array}$ & $\begin{array}{c}\text { Average } \\
\text { identification } \\
\text { accuracy for the } 10 \\
\text { data subsets }(\%)\end{array}$ & $\begin{array}{c}\text { Standard deviation } \\
\text { of the identification } \\
\text { accuracies for the } \\
10 \text { data subsets }\end{array}$ \\
\hline $7000-10000$ & $4: 1$ & 50 & 99.29 & 0.01356 & 98.33 & 0.02833 \\
\hline $7000-10000$ & $5: 1$ & 50 & 99.66 & 0.006296 & 99.33 & 0.01332 \\
\hline $8000-9000$ & $3: 1$ & 50 & 97.79 & 0.04002 & 97.11 & 0.03854 \\
\hline $8000-9000$ & $4: 1$ & 50 & 98.00 & 0.03949 & 96.39 & 0.05423 \\
\hline $8000-9000$ & $5: 1$ & 50 & 97.74 & 0.04030 & 96.67 & 0.04945 \\
\hline $8000-10000$ & $3: 1$ & 10 & 94.12 & 0.1173 & 93.56 & 0.1207 \\
\hline $8000-10000$ & $4: 1$ & 10 & 96.14 & 0.06422 & 95.28 & 0.05700 \\
\hline $8000-10000$ & $5: 1$ & 10 & 97.13 & 0.04351 & 96.67 & 0.05579 \\
\hline $9000-10000$ & $3: 1$ & 50 & 93.89 & 0.08533 & 93.56 & 0.08401 \\
\hline $9000-10000$ & $4: 1$ & 50 & 97.36 & 0.05689 & 96.11 & 0.07049 \\
\hline $9000-10000$ & $5: 1$ & 50 & 97.74 & 0.04076 & 97.00 & 0.05261 \\
\hline
\end{tabular}

smut fungi was provided, and methodological references were also provided for the identification of quarantine wheat smut fungi in the processes of plant quarantine.

A variety of wheat diseases are caused by smut fungi, including wheat common bunt, wheat loose smut, wheat flag smut, wheat dwarf bunt, and wheat Karnal bunt. The diseases caused by wheat smut fungi can cause serious yield losses in production and even losses of up to $100 \%$ under appropriate environmental conditions $[2,11,38]$. In addition, the flour quality can seriously decline due to contamination by the causal agents. Among wheat smut fungi, Tilletia controversa (the causal agent of wheat dwarf bunt) and $T$. indica (the causal agent of wheat Karnal bunt) are two kinds of important entry-exit quarantine pests in many countries. In the processes of import and export wheat quarantine, it is critical to detect and identify the species of wheat smut fungi and the categories of wheat bunt galls carried in wheat. At present, the identification of these pathogens is conducted mainly based on morphological observation [1-5] and molecular biological detection $[2-4,9,11]$. Morphological observation is usually performed by using light microscopy and scanning electron microscopy. Molecular biological methods based on molecular markers, such as intergenic spacer [9], internal transcribed spacer [11], and extension factor [11], have been used to identify wheat smut fungi. NIRS is a rapid and nondestructive analytical technique $[14,15,18,22]$. In this study, a method based on NIRS was provided for identification of the three kinds of wheat smut fungi including $T$. foetida, Ustilago tritici, and Urocystis tritici. In future studies, NIRS can be used to identify other pathogens and an NIRS-based identification system can be developed for the identification of multiple kinds of plant pathogens. Moreover, direct detection of bunt gall and healthy wheat seeds using NIRS can be explored to provide technical support for rapid online detection of imported and exported wheat.

The numbers of acquired near-infrared spectra of the three kinds of pathogens obtained in this study were not equal. There was a considerable difference among the numbers, and the spectra of Urocystis tritici were fewer than those of the other two pathogens. Although all the acquired near-infrared spectra were divided into different data subsets using Data treatment method 2 and relatively perfect results were achieved using the built DPLS, BPNN, and SVM models, the bias in pathogen identification may still be caused by the unbalanced numbers of samples. In further studies, the collection of Urocystis tritici samples and the acquisition of near-infrared spectra of the corresponding samples can be strengthened to obtain more near-infrared spectra of the pathogen and the pathogen identification models can be further optimized to ensure the accurate identification stability of the established models.

Near-infrared spectra contain material information that is useful to identify samples, and some spectral bands associated with material signals play important roles in qualitative analysis $[14,15,18,22]$. To the best of our knowledge, systematic studies on material composition of wheat smut fungi have not been reported. In the future, the studies on this aspect can be conducted to explore mechanisms to interpret the near-infrared spectra of different wheat smut fungi, which is conducive to selecting the suitable modeling spectral region for pathogen identification.

To reduce noise interference and improve the signal-tonoise ratio, the number of scan processes in the measurement system was set as $8 \mathrm{~cm}^{-1}$ when near-infrared spectra of pathogen samples were acquired in this study. In addition, when teliospores were placed into the sample cup, the tightness of the teliospores was kept as consistent as possible to reduce the differences that may be induced by different tightness. Based on original near-infrared spectral data, satisfactory modeling results were obtained using the models built in the simply divided modeling spectral regions in this study. Therefore, no mathematical methods were applied to preprocess the acquired original near-infrared spectral data and no statistical methods were used to perform the modeling spectral region selection. At present, there are a variety of spectral preprocessing methods and modeling spectral region selection methods $[15,22]$. In future studies, original near-infrared spectral data can be preprocessed using the selected suitable method to eliminate background interference that may exist, a suitable method can be chosen 
TABLE 8: Pathogen identification results of the SVM models built with different modeling ratios in each modeling spectral region when Data treatment method 2 was used.

\begin{tabular}{|c|c|c|c|c|c|}
\hline \multirow[b]{2}{*}{$\begin{array}{l}\text { Spectral } \\
\text { region }\left(\mathrm{cm}^{-1}\right)\end{array}$} & \multirow[b]{2}{*}{$\begin{array}{l}\text { Modeling ratio of } \\
\text { training set to } \\
\text { testing set }\end{array}$} & \multicolumn{2}{|c|}{ Training sets } & \multicolumn{2}{|c|}{ Testing sets } \\
\hline & & $\begin{array}{c}\text { Average identification } \\
\text { accuracy for the } 10 \text { data } \\
\text { subsets }(\%)\end{array}$ & $\begin{array}{l}\text { Standard deviation of } \\
\text { the identification } \\
\text { accuracies for the } 10 \\
\text { data subsets }\end{array}$ & $\begin{array}{l}\text { Average identification } \\
\text { accuracy for the } 10 \text { data } \\
\text { subsets }(\%)\end{array}$ & $\begin{array}{l}\text { Standard deviation of } \\
\text { the identification } \\
\text { accuracies for the } 10 \\
\text { data subsets }\end{array}$ \\
\hline $4000-12000$ & $3: 1$ & 99.92 & 0.002280 & 99.78 & 0.006660 \\
\hline $4000-12000$ & $4: 1$ & 99.79 & 0.003254 & 99.17 & 0.02499 \\
\hline $4000-12000$ & $5: 1$ & 99.86 & 0.002720 & 100 & 0 \\
\hline $4000-5000$ & $3: 1$ & 100 & 0 & 99.78 & 0.006660 \\
\hline $4000-5000$ & $4: 1$ & 100 & 0 & 99.72 & 0.008340 \\
\hline $4000-5000$ & $5: 1$ & 100 & 0 & 99.67 & 0.009990 \\
\hline $4000-6000$ & $3: 1$ & 100 & 0 & 99.56 & 0.008880 \\
\hline $4000-6000$ & $4: 1$ & 99.86 & 0.004290 & 99.72 & 0.008340 \\
\hline $4000-6000$ & $5: 1$ & 100 & 0 & 99.67 & 0.009990 \\
\hline $4000-7000$ & $3: 1$ & 100 & 0 & 99.11 & 0.01776 \\
\hline $4000-7000$ & $4: 1$ & 100 & 0 & 99.72 & 0.008340 \\
\hline $4000-7000$ & $5: 1$ & 99.93 & 0.002040 & 100 & 0 \\
\hline $4000-8000$ & $3: 1$ & 100 & 0 & 99.11 & 0.01473 \\
\hline $4000-8000$ & $4: 1$ & 100 & 0 & 99.72 & 0.008340 \\
\hline $4000-8000$ & $5: 1$ & 100 & 0 & 99.67 & 0.009990 \\
\hline $4000-9000$ & $3: 1$ & 100 & 0 & 99.56 & 0.008880 \\
\hline $4000-9000$ & $4: 1$ & 100 & 0 & 98.89 & 0.02545 \\
\hline $4000-9000$ & $5: 1$ & 99.66 & 0.01026 & 98.67 & 0.03055 \\
\hline $4000-10000$ & $3: 1$ & 100 & 0 & 99.56 & 0.008880 \\
\hline $4000-10000$ & $4: 1$ & 99.86 & 0.002840 & 99.17 & 0.02499 \\
\hline $4000-10000$ & $5: 1$ & 99.73 & 0.006261 & 98.67 & 0.03055 \\
\hline $5000-6000$ & $3: 1$ & 99.70 & 0.009150 & 99.33 & 0.01421 \\
\hline $5000-6000$ & $4: 1$ & 99.86 & 0.004290 & 100 & 0 \\
\hline $5000-6000$ & $5: 1$ & 100 & 0 & 99.67 & 0.009990 \\
\hline $5000-7000$ & $3: 1$ & 100 & 0 & 99.33 & 0.01421 \\
\hline $5000-7000$ & $4: 1$ & 100 & 0 & 99.72 & 0.008340 \\
\hline $5000-7000$ & $5: 1$ & 100 & 0 & 99.67 & 0.009990 \\
\hline $5000-8000$ & $3: 1$ & 100 & 0 & 99.11 & 0.01088 \\
\hline $5000-8000$ & $4: 1$ & 100 & 0 & 98.89 & 0.01362 \\
\hline $5000-8000$ & $5: 1$ & 99.86 & 0.002720 & 98.67 & 0.02211 \\
\hline $5000-9000$ & $3: 1$ & 100 & 0 & 99.56 & 0.008880 \\
\hline $5000-9000$ & $4: 1$ & 100 & 0 & 99.72 & 0.008340 \\
\hline $5000-9000$ & $5: 1$ & 99.59 & 0.01233 & 98.67 & 0.03055 \\
\hline $5000-10000$ & $3: 1$ & 100 & 0 & 99.56 & 0.008880 \\
\hline $5000-10000$ & $4: 1$ & 99.86 & 0.002840 & 98.89 & 0.03333 \\
\hline $5000-10000$ & $5: 1$ & 100 & 0 & 99.67 & 0.009990 \\
\hline $6000-7000$ & $3: 1$ & 99.85 & 0.003040 & 99.34 & 0.01017 \\
\hline $6000-7000$ & $4: 1$ & 99.86 & 0.002840 & 98.33 & 0.03333 \\
\hline $6000-7000$ & $5: 1$ & 99.80 & 0.003116 & 99.00 & 0.01526 \\
\hline $6000-8000$ & $3: 1$ & 99.92 & 0.002280 & 98.89 & 0.01110 \\
\hline $6000-8000$ & $4: 1$ & 100 & 0 & 99.17 & 0.01274 \\
\hline $6000-8000$ & $5: 1$ & 99.93 & 0.002040 & 98.67 & 0.01631 \\
\hline $6000-9000$ & $3: 1$ & 99.92 & 0.002280 & 99.11 & 0.01473 \\
\hline $6000-9000$ & $4: 1$ & 99.86 & 0.002840 & 98.61 & 0.03345 \\
\hline $6000-9000$ & $5: 1$ & 99.86 & 0.002720 & 99.00 & 0.01526 \\
\hline $6000-10000$ & $3: 1$ & 99.92 & 0.002280 & 99.56 & 0.008880 \\
\hline $6000-10000$ & $4: 1$ & 99.86 & 0.002840 & 98.61 & 0.03345 \\
\hline $6000-10000$ & $5: 1$ & 99.93 & 0.002040 & 99.67 & 0.009990 \\
\hline $7000-8000$ & $3: 1$ & 100 & 0 & 99.11 & 0.01088 \\
\hline $7000-8000$ & $4: 1$ & 99.72 & 0.004734 & 98.89 & 0.02545 \\
\hline $7000-8000$ & $5: 1$ & 100 & 0 & 99.33 & 0.01332 \\
\hline 7000-9000 & $3: 1$ & 99.77 & 0.006870 & 99.11 & 0.01088 \\
\hline 7000-9000 & $4: 1$ & 99.86 & 0.002840 & 98.61 & 0.02241 \\
\hline $7000-9000$ & $5: 1$ & 100 & 0 & 99.33 & 0.01333 \\
\hline $7000-10000$ & $3: 1$ & 99.85 & 0.004590 & 99.33 & 0.01017 \\
\hline
\end{tabular}


TABLE 8: Continued.

\begin{tabular}{lccccc}
\hline Spectral & $\begin{array}{c}\text { Training sets } \\
\text { Modeling ratio of } \\
\text { region }\left(\mathrm{cm}^{-1}\right)\end{array}$ & $\begin{array}{c}\text { Testing sets } \\
\text { training set to } \\
\text { testing set } \\
\text { Average identification } \\
\text { the identification } \\
\text { accuracy for the 10 data } \\
\text { subsets (\%) } \\
\text { data subsets }\end{array}$ & $\begin{array}{c}\text { Standard deviation of } \\
\text { the identification } \\
\text { accuracies for the } 10 \\
\text { data subsets }\end{array}$ \\
\hline $7000-10000$ & $4: 1$ & 99.86 & 0.002840 & 98.89 & 0.01844 \\
$7000-10000$ & $5: 1$ & 99.86 & 0.004110 & 99.33 & 0.01332 \\
$8000-9000$ & $3: 1$ & 99.77 & 0.004893 & 98.00 & 0.01554 \\
$8000-9000$ & $4: 1$ & 99.86 & 0.002840 & 98.33 & 0.02224 \\
$8000-9000$ & $5: 1$ & 99.73 & 0.006261 & 98.33 & 0.02236 \\
$8000-10000$ & $3: 1$ & 99.92 & 0.002280 & 99.56 & 0.01332 \\
$8000-10000$ & $4: 1$ & 99.79 & 0.004573 & 98.61 & 0.03345 \\
$8000-10000$ & $5: 1$ & 99.80 & 0.004381 & 99.00 & 0.02135 \\
$9000-10000$ & $3: 1$ & 99.70 & 0.005065 & 98.67 & 0.02266 \\
$9000-10000$ & $4: 1$ & 99.57 & 0.005715 & 98.06 & 0.03298 \\
$9000-10000$ & $5: 1$ & 99.52 & 0.005344 & & 0.01631 \\
\hline
\end{tabular}

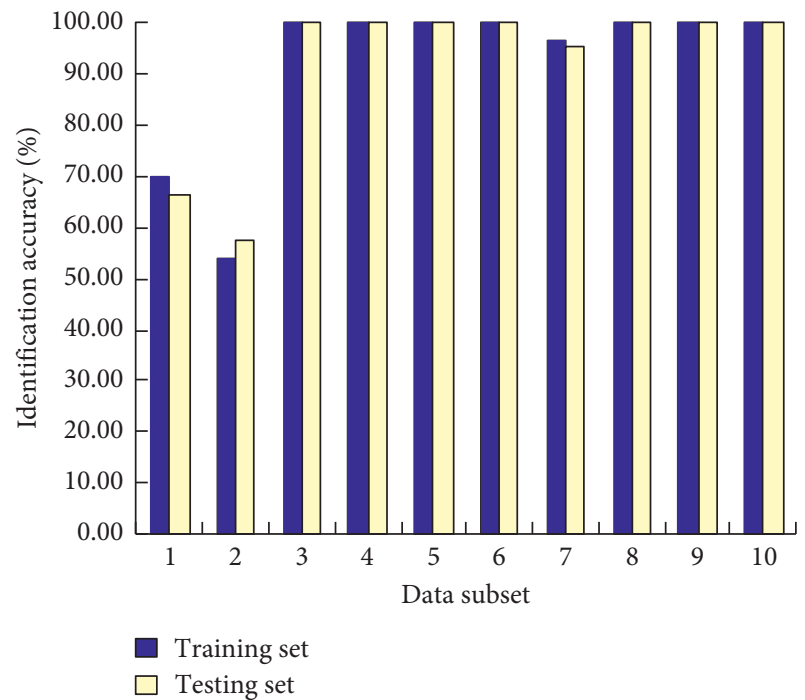

FIGURE 3: Pathogen identification results of the BPNN models built in the modeling spectral region of $4000-5000 \mathrm{~cm}^{-1}$ with a ratio of the training set to the testing set of $3: 1$ and the number of neurons in the hidden layer equal to 50 on each data subset when Data treatment method 2 was used.

to select the optimal modeling spectral region, and then the modeling results can be compared to the results obtained in this study to select the optimal modeling method.

The results obtained in this study demonstrated that the modeling effect may be affected by the spectral data used in modeling. For example, when Data treatment method 2 was used and the BPNN models were built with the modeling ratio of $3: 1$ or $5: 1$ in the spectral region of $4000-5000 \mathrm{~cm}^{-1}$, with the modeling ratio of $4: 1$ in the spectral region of $5000-6000 \mathrm{~cm}^{-1}$, with the modeling ratio of $3: 1$ or $5: 1$ in the spectral region of $6000-7000 \mathrm{~cm}^{-1}$, or with the modeling ratio of $3: 1$ in the spectral region of $8000-10000 \mathrm{~cm}^{-1}$, relatively small averages and large SD values of identification accuracies of the training and testing sets on the 10 data subsets were obtained. This was mainly due to the low identification accuracies of the training and testing sets for the model built on some data subset. In comparison, it was more likely to achieve satisfactory identification results when modeling was conducted in a relatively wide spectral region.

In this study, good identification results were obtained using the three modeling methods including DPLS, BPNN, and SVM. When Data treatment method 1 or Data treatment method 2 was used, a DPLS, BPNN, or SVM model with satisfactory identification accuracies of the training and testing sets could be obtained. In practical applications, one of the modeling methods can be used or more than one modeling methods can be used to synthetically verify identification results, according to the situation. However, in comparison, DPLS is the most stable, followed by SVM then BPNN. In this study, only three modeling methods (DPLS, BPNN, and SVM) were used to build the pathogen identification models. However, many modeling methods for qualitative identification analyses have been reported $[15,22,24]$. In further studies, other modeling methods can be used in an attempt for classification, discrimination, and identification of wheat smut fungi.

In this study, the identification of the three kinds of wheat smut fungi was investigated based on NIRS, aiming to provide a method for the rapid and nondestructive detection and identification of wheat smut fungi. According to the method proposed in this study, the teliospores of related pathogens can be obtained from wheat plants with the symptoms of wheat smuts in the field, then the near-infrared spectra can be acquired using a near-infrared spectrometer in the laboratory, and finally the samples can be identified using the built models. If possible, a portable near-infrared spectrometer can be developed for direct detection of wheat smut fungi in the field. In production practice, wheat smuts are mainly controlled by using seed treatment measures besides utilization of resistant cultivars. Pathogen identification can avoid reserving wheat seeds from the diseased fields and the further transfer of wheat seeds after reservation and can provide a basis for countermeasures. The results of this study provide a methodological reference for performing this task. Once wheat plants are infected by smut fungi, the hyphae expand inside the leaves, and during the 
later stage of disease progress, typical symptoms appear and teliospores are produced. Therefore, to perform early detection of the related diseases, studies on the detection of infected wheat plants based on NIRS should be conducted as well as studies on early detection of wheat stripe rust and wheat leaf rust mentioned above [30-32].

\section{Data Availability}

The data used to support the findings of this study are included within the article and the supplementary information files.

\section{Conflicts of Interest}

The authors declare that there are no conflicts of interest regarding the publication of this paper.

\section{Authors' Contributions}

Yaqiong Zhao and Feng Qin contributed equally to this paper.

\section{Acknowledgments}

This study was supported by the National Key Research and Development Program of China (2018YFD0200402), the National Key Technologies Research and Development Program of China (2012BAD19BA04), and the International Research Exchange Scheme of the Marie Curie Program of the 7th Framework Program (ref. PIRSES-GA-2013612659).

\section{Supplementary Materials}

Table S1: pathogen identification results of the DPLS models built with different modeling ratios and numbers of principal components in each modeling spectral region when Data treatment method 1 was used. Table S2: pathogen identification results of the BPNN models built with different modeling ratios and numbers of neurons in the hidden layer in each modeling spectral region when Data treatment method 1 was used. Table S3: pathogen identification results of the DPLS models built on each data subset with different modeling ratios and numbers of principal components in each modeling spectral region when Data treatment method 2 was used. Table S4: pathogen identification results of the BPNN models built on each data subset with different modeling ratios and numbers of neurons in the hidden layer in each modeling spectral region when Data treatment method 2 was used. Table S5: pathogen identification results of the SVM models built on each data subset with different modeling ratios in each modeling spectral region when Data treatment method 2 was used. (Supplementary Materials)

\section{References}

[1] V. O. Stockwell and E. J. Trione, "Distinguishing teliospores of Tilletia controversa from those of T. Cariesby fluorescence microscopy," Plant Disease, vol. 70, no. 10, pp. 924-926, 1986.
[2] H. G. Wang, H. Y. Zhu, Z. H. Ma, L. Liu, and G. X. Zhang, "The progress and prospect in research on wheat dwarf bunt," Review of China Agricultural Science and Technology, vol. 7, no. 4, pp. 21-27, 2005.

[3] W. Dong, W. Q. Chen, and T. G. Liu, "Identification and detection methods of Tilletia controversa Kühn," Plant Protection, vol. 33, no. 6, pp. 128-131, 2007.

[4] L. Guo, "Taxonomy of smut fungi in China: a brief review," Mycosystema, vol. 34, no. 5, pp. 817-820, 2015.

[5] H. X. Yu, L. Gao, X. H. Kang, T. G. Liu, B. Liu, and W. Q. Chen, "Discrimination of teliospores in TCK and TFL with laser scanning confocal microscope," China Plant Protection, vol. 36, no. 2, pp. 5-8, 2016.

[6] J. G. Mcdonald, E. Wong, G. T. Kristiansson, and G. P. White, "Direct amplification by PCR of DNA from ungerminated teliospores of Tilletia species," Canadian Journal of Plant Pathology, vol. 21, no. 1, pp. 78-80, 1999.

[7] G. Bakkeren, J. W. Kronstad, and C. A. Levesque, "Comparison of AFLP fingerprints and ITS sequences as phylogenetic markers in Ustilaginomycetes," Mycologia, vol. 92, no. 3, pp. 510-521, 2000.

[8] R. D. Frederick, K. E. Snyder, P. W. Tooley et al., "Identification and differentiation of Tilletia indica and T. walkeri using the polymerase chain reaction," Phytopathology, vol. 90, no. 9, pp. 951-960, 2000.

[9] H. Liang, Y. L. Peng, G. Z. Zhang, W. Q. Chen, and T. G. Liu, "Amplification and sequence analysis of the rDNA intergenic spacer (rDNA-IGS) from three Tilletia species," Acta Phytopathologica Sinica, vol. 36, no. 5, pp. 407-412, 2006.

[10] Y. Y. Cao, L. F. Wang, L. P. Duan et al., "Development of a real-time fluorescence loop-mediated isothermal amplification assay for rapid and quantitative detection of Ustilago maydis," Scientific Reports, vol. 7, article 13394, 2017.

[11] K. G. Savchenko, L. M. Carris, J. Demers, D. S. Manamgoda, and L. A. Castlebury, "What causes flag smut of wheat?," Plant Pathology, vol. 66, no. 7, pp. 1139-1148, 2017.

[12] N. W. Schaad and R. D. Frederick, "Real-time PCR and its application for rapid plant disease diagnostics," Canadian Journal of Plant Pathology, vol. 24, no. 3, pp. 250-258, 2002.

[13] S. Sankaran, A. Mishra, R. Ehsani, and C. Davis, "A review of advanced techniques for detecting plant diseases," Computers and Electronics in Agriculture, vol. 72, no. 1, pp. 1-13, 2010.

[14] G. T. Xu, H. F. Yuan, and W. Z. Lu, "Development of modern near-infrared spectroscopic techniques and its applications," Spectroscopy and Spectral Analysis, vol. 20, no. 2, pp. 134-142, 2000.

[15] Y. L. Yan, L. L. Zhao, D. H. Han, and S. M. Yang, Basis and Application of Near-infrared Reflectance Spectroscopy, China Light Industry Press, Beijing, China, 2005.

[16] Q. Chen, J. Zhao, M. Liu, J. Cai, and J. Liu, "Determination of total polyphenols content in green tea using FT-NIR spectroscopy and different PLS algorithms," Journal of Pharmaceutical and Biomedical Analysis, vol. 46, no. 3, pp. 568-573, 2008.

[17] M. K. Ahmed and J. Levenson, “Application of near-infrared spectroscopy to the quality assurance of ethanol and butanol blended gasoline," Petroleum Science and Technology, vol. 30, no. 2, pp. 115-121, 2012.

[18] X. L. Chu and W. Z. Lu, "Research and application progress of near-infrared spectroscopy analytical technology in China in the past five years," Spectroscopy and Spectral Analysis, vol. 34, no. 10, pp. 2595-2605, 2014.

[19] H. Chen, Z. Lin, H. Wu, L. Wang, T. Wu, and C. Tan, "Diagnosis of colorectal cancer by near-infrared optical fiber 
spectroscopy and random forest," Spectrochimica Acta Part A: Molecular and Biomolecular Spectroscopy, vol. 135, pp. 185191, 2015.

[20] N. Liu, H. A. Parra, A. Pustjens, K. Hettinga, P. Mongondry, and S. M. van Ruth, "Evaluation of portable near-infrared spectroscopy for organic milk authentication," Talanta, vol. 184, pp. 128-135, 2018.

[21] M. Lopo, C. A. Teixeira dos Santos, R. N. M. J. Páscoa, A. R. Graça, and J. A. Lopes, "Near-infrared spectroscopy as a tool for intensive mapping of vineyards soil," Precision Agriculture, vol. 19, no. 3, pp. 445-462, 2018.

[22] C. Pasquini, "Near-infrared spectroscopy: a mature analytical technique with new perspectives-a review," Analytica Chimica Acta, vol. 1026, pp. 8-36, 2018.

[23] P. I. Monteiro, J. S. Santos, V. R. Alvarenga Brizola et al., "Comparison between proton transfer reaction mass spectrometry and near-infrared spectroscopy for the authentication of Brazilian coffee: a preliminary chemometric study," Food Control, vol. 91, pp. 276-283, 2018.

[24] D. Granato, P. Putnik, D. B. Kovačević et al., "Trends in chemometrics: food authentication, microbiology, and effects of processing," Comprehensive Reviews in Food Science and Food Safety, vol. 17, no. 3, pp. 663-677, 2018.

[25] J. Perez-Mendoza, J. E. Throne, F. E. Dowell, and J. E. Baker, "Chronological age-grading of three species of stored-product beetles by using near-infrared spectroscopy," Journal of Economic Entomology, vol. 97, no. 3, pp. 1159-1167, 2004.

[26] J. Perez-Mendoza, J. E. Throne, E. B. Maghirang, F. E. Dowell, and J. E. Baker, "Insect fragments in flour: relationship to lesser grain borer (Coleoptera: bostrichidae) infestation level in wheat and rapid detection using near-infrared spectroscopy," Journal of Economic Entomology, vol. 98, no. 6, pp. 2282-2291, 2005.

[27] D. Wu, L. Feng, C. Q. Zhang, and Y. He, "Early detection of gray mold (Cinerea) on eggplant leaves based on vis/nearinfrared spectra," Journal of Infrared and Millimeter Waves, vol. 26, no. 4, pp. 269-273, 2007.

[28] L. Feng, S. S. Chen, B. Feng, F. Liu, Y. He, and B. G. Lou, "Early detection of soybean pod anthracnose based on spectrum technology," Transactions of the Chinese Society of Agricultural Engineering, vol. 28, no. 1, pp. 139-144, 2012.

[29] Y. D. Liu, H. C. Xiao, Q. Deng, Z. C. Zhang, X. D. Sun, and Y. S. Xiao, "Nondestructive detection of citrus greening by near-infrared spectroscopy," Transactions of the Chinese Society of Agricultural Engineering, vol. 32, no. 14, pp. 202-208, 2016.

[30] X. L. Li, Z. H. Ma, L. L. Zhao, J. H. Li, and H. G. Wang, "Early diagnosis of wheat stripe rust and wheat leaf rust using nearinfrared spectroscopy," Spectroscopy and Spectral Analysis, vol. 33, no. 10, pp. 2661-2665, 2013.

[31] X. L. Li, F. Qin, L. L. Zhao, J. H. Li, Z. H. Ma, and H. G. Wang, "Detection of Puccinia striiformis f. sp. tritici latent infections in wheat leaves using near-infrared spectroscopy technology," Spectroscopy and Spectral Analysis, vol. 34, no. 7, pp. 18531858, 2014.

[32] Y. Q. Zhao, Y. L. Gu, F. Qin et al., "Application of nearinfrared spectroscopy to quantitatively determine relative content of Puccnia striiformis f. sp. tritici DNA in wheat leaves in incubation period," Journal of Spectroscopy, vol. 2017, Article ID 9740295, 12 pages, 2017.

[33] X. L. Li, F. Qin, L. L. Zhao, J. H. Li, Z. H. Ma, and H. G. Wang, "Identification and classification of disease severity of wheat stripe rust using near-infrared spectroscopy technology,"
Spectroscopy and Spectral Analysis, vol. 35, no. 2, pp. 367-371, 2015.

[34] X. L. Li, Z. H. Ma, L. L. Zhao, J. H. Li, and H. G. Wang, "Application of near-infrared spectroscopy to qualitative identification and quantitative determination of Puccinia striiformis f. sp. tritici and $P$. recondita f. sp. tritici," Spectroscopy and Spectral Analysis, vol. 34, no. 3, pp. 643-647, 2014.

[35] Y. Q. Zhao, F. Qin, P. Cheng et al., "Quantitative determination of germinability of Puccinia striiformis f. sp. tritici urediospores using near-infrared spectroscopy technology," Journal of Spectroscopy, vol. 2015, Article ID 384214, 8 pages, 2015.

[36] P. Cheng, X. L. Li, F. Qin et al., "Effects of UV-B radiation on near-infrared spectroscopy and identification of Puccinia striiformis f. sp. tritici," Journal of Spectroscopy, vol. 2014, Article ID 751458, 9 pages, 2014.

[37] C. C. Chang and C. J. Lin, "LIBSVM," ACM Transactions on Intelligent Systems and Technology, vol. 2, no. 3, pp. 1-27, 2011.

[38] L. H. Purdy, "Flag smut of wheat," The Botanical Review, vol. 31, no. 4, pp. 565-606, 1965. 

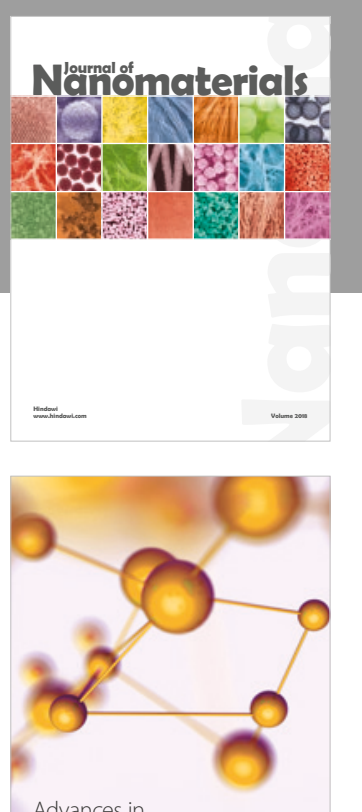

Physical Chemistry
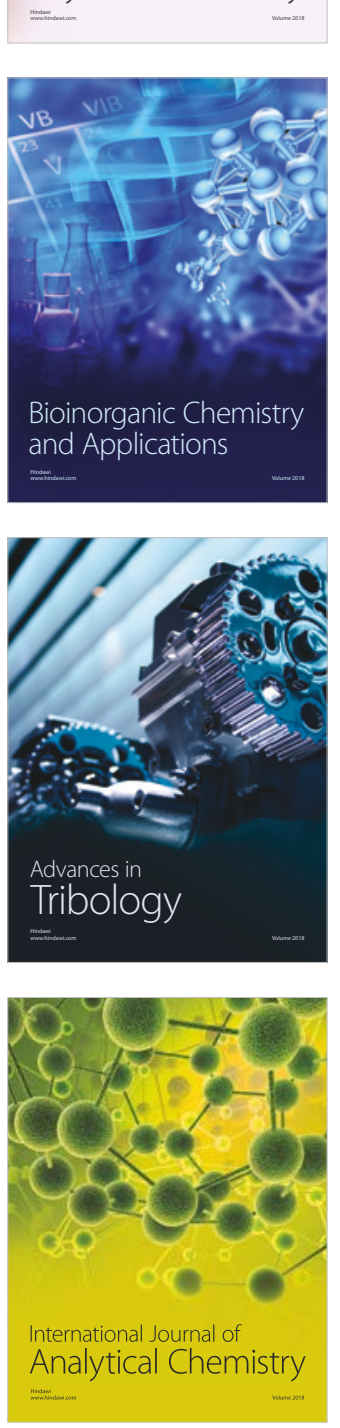

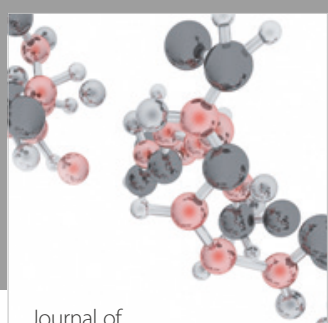

Analytical Methods

in Chemistry

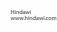

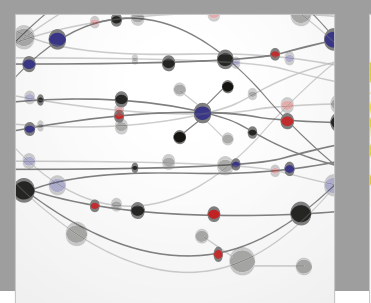

The Scientific World Journal

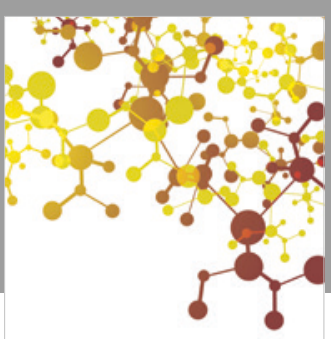

Journal of

Applied Chemistry
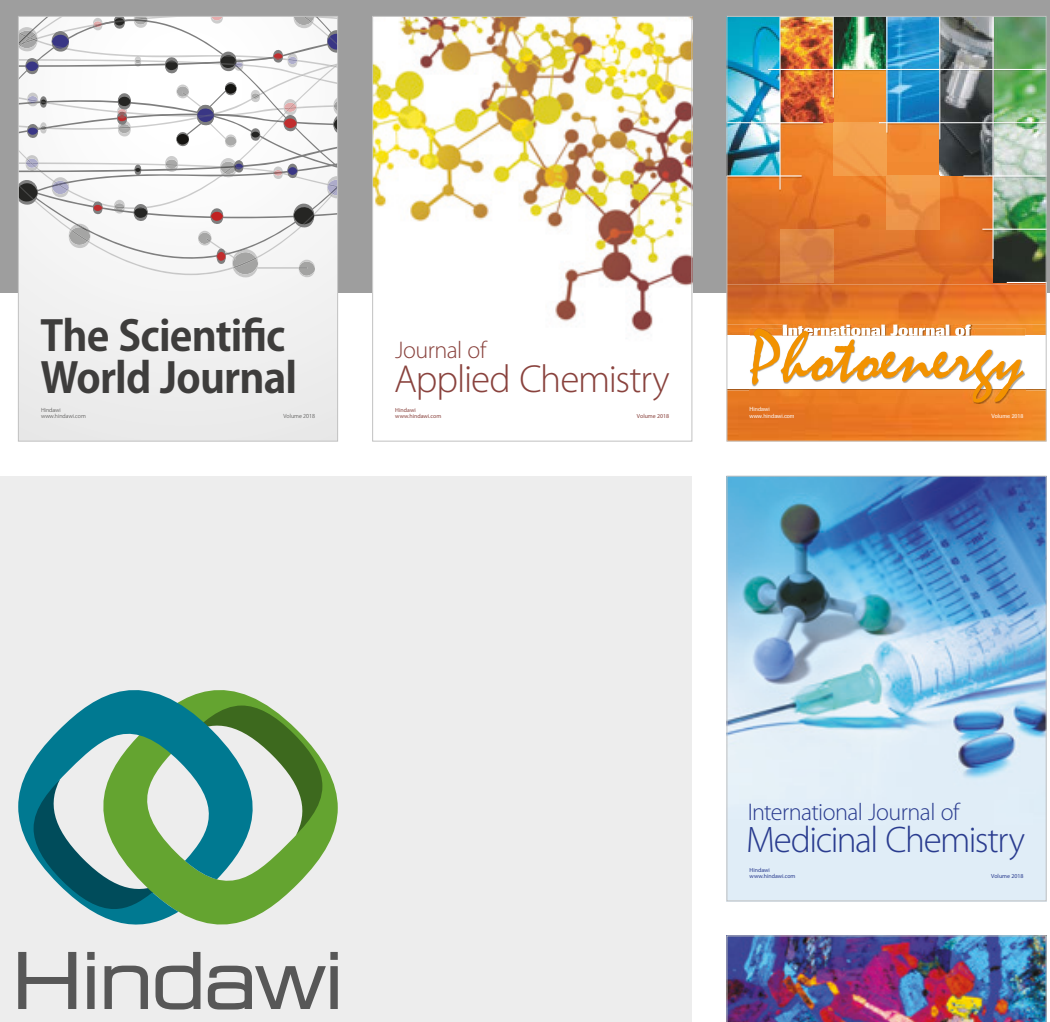

Submit your manuscripts at

www.hindawi.com
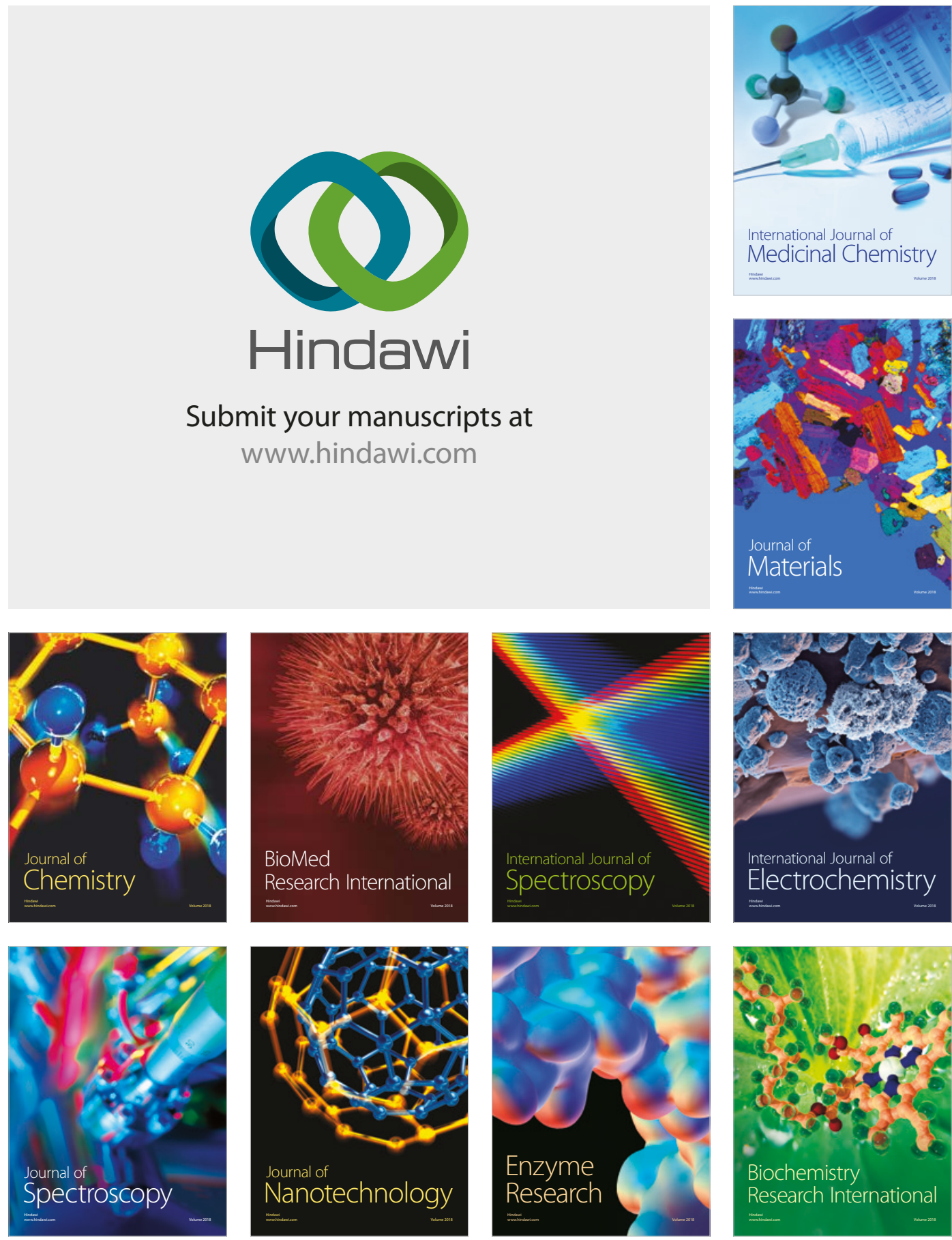
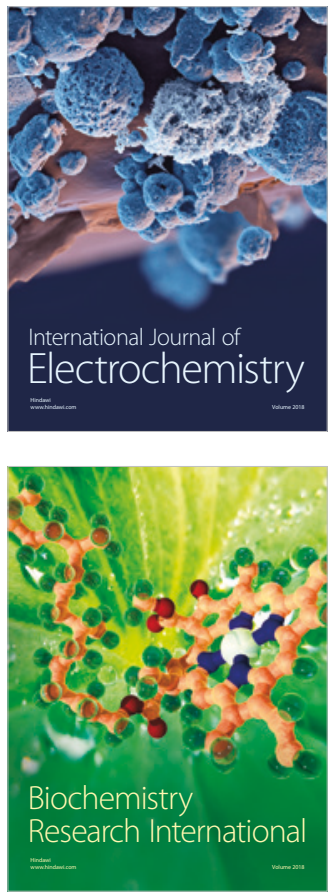